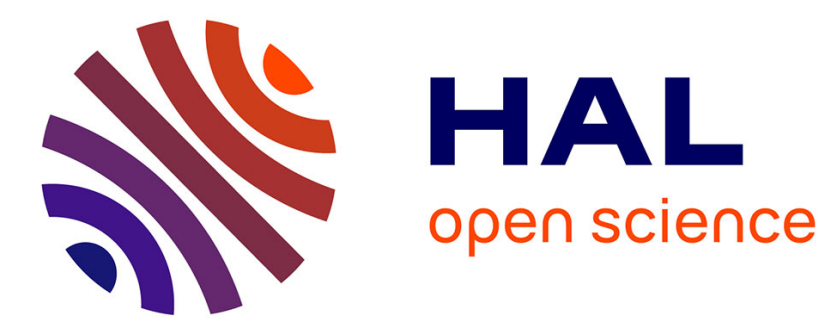

\title{
Urban costs, Trade Costs and Tax Competition
}

Fabien Candau

\section{- To cite this version:}

Fabien Candau. Urban costs, Trade Costs and Tax Competition. Revue d'Economie Politique, 2008, 118, pp.625-661. hal-01844386

\section{HAL Id: hal-01844386 https: / hal-univ-pau.archives-ouvertes.fr/hal-01844386}

Submitted on 19 Jul 2018

HAL is a multi-disciplinary open access archive for the deposit and dissemination of scientific research documents, whether they are published or not. The documents may come from teaching and research institutions in France or abroad, or from public or private research centers.
L'archive ouverte pluridisciplinaire HAL, est destinée au dépôt et à la diffusion de documents scientifiques de niveau recherche, publiés ou non, émanant des établissements d'enseignement et de recherche français ou étrangers, des laboratoires publics ou privés. 


\title{
Urban costs, Trade costs and Tax Competition.
}

\author{
Fabien Candau
}

October 6, 2008

\begin{abstract}
This paper presents a model of the New Economic Geography which integrates commuting costs and land rent and displays a dispersion - agglomeration configuration when regional and/or international trade are liberalised. Two main results are found, the first one is that dispersion Pareto dominates agglomeration, the second one is that the agglomeration rent is not bell-shaped but strictly decreasing when impediments to trade are removed. This turns out to be a convenient framework to revisit the links between tax competition, location of firms and trade integration. It is shown in particular that a reduction in trade costs and/or an increase in urban costs leads to a race to the bottom in terms of taxation, and that a tax floor set at the level of the small country may be detrimental to it. Lastly two extensions are done in order to show that i) even under a partial agglomeration of activities, the race to the bottom in terms of taxation is still verified ii) even in a multi-regions model, international trade liberalization generates a race to the bottom when regional trade costs are low enough.
\end{abstract}

Economic geography - Agglomeration - Trade - Race to the bottom.

\section{Concurrence Fiscale, Ville et Commerce.}

Cet article présente un modèle de la Nouvelle Economie Géographique qui intègre coût de navette et rente foncière. L'introduction de ces éléments dispersifs, importés de l'économie urbaine, permet d'observer qu'un accroissement de l'intégration commerciale entraîne une dispersion des activités. Deux résultats majeurs sont mis en avant, premièrement nous observons que l'équilibre de dispersion est Pareto dominant par rapport à l'équilibre aggloméré, ce résultat contraste avec les résultats obtenus par ailleurs, deuxièmement la rente d'agglomération qui prend la forme d'une courbe en cloche dans tous les modèles d'économie géographique est ici strictement décroissante. Cette propriété est lourde de conséquence en matière fiscale, nous dé- 
montrons tout d'abord que seule une course vers le bas des taux d'imposition est alors envisageable (lorsque le commerce est libéralisé où lorsque les coûts urbains augmentent) puis qu'une politique d'harmonisation fiscale allant dans le sens d'une taxe plancher pour les pays périphériques tend à ne plus être Pareto optimale. Enfin deux extensions sont réalisées en vue de montrer que le comportement de moins disant fiscal observé dans le cas d'une agglomeration totale est vérifié i) lorsque l'agglomeration est partielle ii) lorsque l'on utilise un modèle à plusieurs régions.

\section{Economie Géographique - Agglomération - Commerce - Moins disant fiscal.}

Classification JEL : H0O, H87, F2, F12.

\section{Introduction}

The relationship between tax competition and integration has been at the heart of many lively debates in the past and remains important and controversial.

Important because the entry of ten new members in the European Union (EU) promises challenges for both old and new members. These challenges seem scary to some countries of the old EU because integration might imply delocalization of some activities and unemployment of the less skilled workers. Hence, to retain activities a decrease in the taxation on the mobile base might be a solution, but if this decrease is copied, and thus degenerates into a race to the bottom, then the resources of the "welfare state" might be reduced and the situation of unskilled workers could be even worse. Besides, the relationship between tax competition and integration is controversial because while the previous fears are supported by the conclusions of the Neoclassical Tax Competition Models (NTCM), the New Economic Geography (NEG) tends to prove the reverse.

According to Zodrow and Mieszkowski [1986] capital mobility makes tax competition wasteful since a rise in one country's tax rate increases capital supply in other regions. As government does not take into account this effect on other countries' capital supply, tax rates and thus public good provisions are inefficiently low. However such a result only hold if governments take care about welfare of their residents, indeed in the case of bad governance tax competition tames the Leviathan (Edwards and Keen [1996]). A large literature has emerged around these two opposite axis but common points are numerous, for instance perfect competition between firms is often assumed and the economic integration is only considered as an integration of capital markets. But labour integration, at least for skilled workers, and trade integration also matters. As does imperfect competition between firms on tax competition between governments. 
Recently the New Economic Geography has challenged this point view. ${ }^{1}$ The most salient result is that under imperfect competition, agglomeration economies generate in a first step of trade integration an increasing rent for capital owners, this rent later decreases, which implies that before the race to the bottom, a race to the top occurs for intermediate levels of transaction costs. But does this bellshaped configuration, which is the heart and soul of conclusions when it comes to tax competition, always occurs whatever the nature of the tax base?

To answer, the present theoretical work goes beyond the national scale and focuses on tax competition concerning labour and thus analyses the regional and urban scale. Indeed much of the cross-border movement of persons is more accurately characterized as inter-municipal or inter-regional rather than inter-country. So, if the mobility of people is at the source of local tax competition ${ }^{2}$ then it is certainly relevant to consider these geographical units. Such a choice lead us to integrate tax competition in models where the cost of living is more accurately defined. Indeed until now all the literature has focused on "international trade model" in the sense that the cost of living in these models only depends on trade costs which leads to a result that cannot be realistic at the urban scale: the cost of living is smaller in the agglomerated area than in the periphery (because all goods are produced there and then consumers do not pay trade costs). We thus firstly analyse tax competition in the Krugman and Livas [1996] model which links the cost of living to urban costs. These costs by impacting on location choice change the outlook of tax competition: only a race to the bottom can be generated by trade integration ${ }^{3}$. By making rigorously urban costs endogenous, the Krugman and Livas model is then an useful tool, however this framework is also very specific, in particular it generates a total agglomeration of activities which is clearly an extreme case that weaken the generality of our result. To resolve this drawback we next turn to the Fujita, Krugman and Venables [1999, chap 18] model which generates a partial agglomeration of activities. With this setting we generalize the race to the bottom result and thus

\footnotetext{
${ }^{1}$ See for instance Andersson and Forslid [2003], Baldwin and Krugman [2004], Borck and Pflüger [2006], Ludema and Wooton [2000], Ottaviano and Van Ypersele [2005], Baldwin and Forslid [2002]. See Candau [2008.a] and Baldwin et al. [2003, chapter 15-16] for surveys.

${ }^{2}$ Tax competition without mobility but by tax comparison is also possible (see for instance Besley and Smart [2007] concerning yardstick competition)

${ }^{3}$ This research is in accordance with the recent discussion concerning the future of the New Economic Geography made by Fujita and Mori [2005, p17] who point out that the Baldwin and Krugman [2004] model is central because it has set up a link between urban economics, which assigns an important role to city government and the NEG, which neglects such an entity. However, as they underline, "the next step would be to graft various urban features - such as land and housing markets, commuting, transportation networks and other urban infrastructure - onto geographical models with local governments".
} 
reverse the conclusion of Borck and Pflüger $[2006]^{4}$ who were the sole before us to analyse tax competition under this scheme of partial agglomeration. At this stage it is important to notice that the both models (Krugman and Livas as well as Fujita, Krugman and Venables) integrate a rest of the world with which cities trade. As a direct consequence, this assumption enables us to study the effect of international trade integration on tax competition, an analysis that has not been done until now. Indeed the literature only analyses bilateral interactions i.e. tax competition of cross border countries when trade between these countries is liberalized, then the relationship between external openning and local tax competition is lacking. We show that regional as well as international trade integration lead to a race to the bottom. In order to check the robustness of this result, we decide to use a model which presents a more aggregated geographical analysis: the Monfort and Nicolini model. This multi-regions model, which drops urban costs, allows to prove that if local trade (i.e between regions of one country) is free enough, a race to the bottom is also generated by the process of international trade liberalization (between countries). Such a conclusion may be instructive for future trade integrations in the European Union.

The paper is divided into four sections. The first and second revisit the Krugman and Livas model in the sense that new results are obtained among which a Pareto domination of the dispersed equilibrium and a decreasing agglomeration rent. The third integrates tax competition under total and partial agglomeration. Lastly the fourth step checks the robustness of the result by integrating tax competition in a competing framework with four regions and no urban cost (the Monfort and Nicolini [2000] model).

\section{Krugman and Livas Elizondo's model revisited}

We present the model of the underlying economy before turning to the tax competition game. The model we adopt is the Krugman and Livas Elizondo [1996] model. This model is presented in details which allows to obtain new results concerning spatial equilibria and welfare.

\subsection{Space pattern}

There are three regions in this model, two monocentric cities and the rest of the world. Furthermore labour is the only factor of production. Entrepreneurs, (denoted $h, h^{*}, h^{\circ}$ in the North, South and rest of the world), own this labour and are mobile

\footnotetext{
${ }^{4}$ Indeed they have shown that only a race to the top was possible in a variant of the Krugman [1991] model.
} 
between cities, but not between cities and the rest of the world. The wage in the latter is taken as the numéraire. Moreover entrepreneurs are also mobile inside the city. Each of them owns one land unit and they are spread along a line, but as all firms are located in the middle of this line (called the Central Business District (CBD)) they need to commute. These commuting costs have a direct impact on the labour force that entrepreneurs supply in the CBD. As each of them owns one labour unit, the total amount supplied by an entrepreneur who lives on the fringe of the city in the North, at location $x$ (the CBD being at location 0 by convention) is :

$$
s(x)=(1-2 \theta|x|),
$$

where $\theta$ (with $\theta<1$ ) is entrepreneurs' level of commuting costs. Furthermore, as the number of entrepreneurs is $h$, entrepreneurs' maximal distance from the CBD is $\frac{h}{2}$, thus the total labour supply net of commuting costs in one city is equal to:

$$
L=\int_{-h / 2}^{h / 2} s(x) d x=h(1-\theta h / 2)
$$

As land rent on both edges of the segments is normalized to zero, if $w$ is entrepreneurs' wages near the CBD, then the wage net of commuting costs earned on both edges is:

$$
s(h / 2) w=s(-h / 2) w=(1-\theta h) w .
$$

Because consumers are identical in terms of preference and income, in equilibrium they must reach the same utility level, so that entrepreneurs who live on the fringe of the segment receive a net wage of only $(1-\theta h) w$, but pay no land rent. On the contrary entrepreneurs who lives near the CBD do not pay significant commuting costs, but the price of the services yielded by land is higher at this location. In other words, the increase in real wage near central places offsets land rent. Figure 1 depicts this situation. 


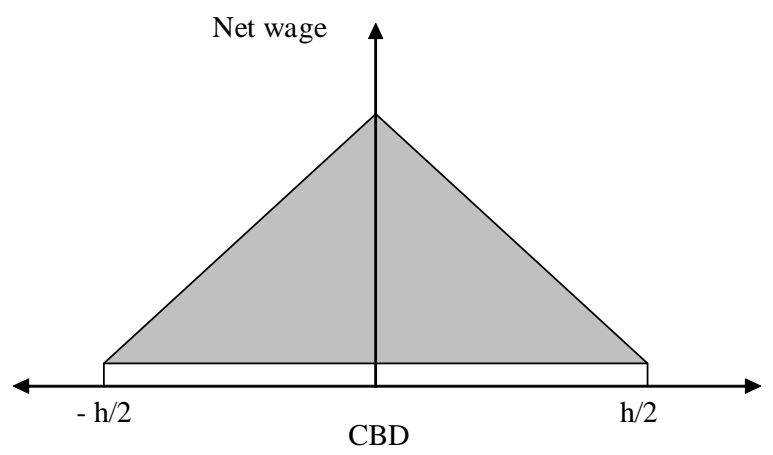

Land rent

Figure 1: Land rent

In Figure 1, the vertical axis measures the net wage in the city, while the horizontal axis shows the size of this city. Because each entrepreneur owns one land unit, this size only depends on their number. Moving from the suburb to the CBD implies a decrease in commuting and therefore an increase in net wage, but also an equivalent increase in land rent which equalizes utility among individuals. In other words, the condition $s(x) w-R(x)=(1-\theta h) w$ must be verified, where $s(x)$ is the total amount supplied by an entrepreneur who lives on the fringe of the CBD, and $R(x)$ is the land rent prevailing at $x$, while the right term $(1-\theta h) w$ represents the wage net of commuting costs earned on both edges given by (3). By using expressions (1) into this system we find the following land rent: $R(x)=\theta(h-2|x|) w$ with $x \in(-1 / 2,1 / 2)$. Thanks to that we can find the Aggregate Land Rents (ALR), $A L R=\int_{-h / 2}^{h / 2} R(x) d x=\theta h^{2} w / 2$. While on the one hand Tabuchi [1998] assumes that there are absentee landlords, and on the other hand, Helpman [1998] assumes that the aggregate land rent is owned at global level, here Krugman and Livas Elizondo [1996] suppose that each entrepreneur owns an equal share of the ALR where they reside. Thus their non salarial income is:

$$
\frac{A L R}{h}=\frac{\theta h w}{2} .
$$

We can now turn to consumers' behavior. 


\subsection{Consumers' behavior}

All consumers share the same utility function and consume one industrial good, composite of different varieties:

$$
U=M \quad \text { with } \quad M=\left[\int_{0}^{N} m_{i}^{\frac{\sigma-1}{\sigma}} d i\right]^{\frac{\sigma}{\sigma-1}}
$$

where $M$ is the consumption of a manufactures aggregate, $N$ is the large number of potential varieties and $\sigma>1$ is the elasticity of substitution among these varieties. All the nominal income (denoted $Y$ ) is spent on manufactures. The budget constraint is then given by:

$$
\begin{aligned}
P M & =Y \\
P & =\left[\int_{i=0}^{N} p_{i}^{1-\sigma}\right]^{1 /(1-\sigma)}
\end{aligned}
$$

which is a decreasing function of the number of varieties produced $N$ (because $1-\sigma<0) . p_{i}$ is the price of a typical variety $i$. The impact of $N$ on the price index is influenced by the elasticity of substitution. The more differentiated the product varieties, the greater the reduction in the price index. The maximization problem gives the following uncompensated demand for manufactures :

$$
m_{i}=\frac{Y}{P^{1-\sigma}} p_{i}^{-\sigma}, \text { with } Y=h\left(1-\frac{\theta}{2} h\right) w,
$$

where $\left(1-\frac{\theta}{2} h\right)$ comes from the income of land ownership $(\theta h w / 2)$ and from the wage net of commuting costs $((1-\theta h) w)$. From that and the price index expression we can see that an increase in the number of industrial products depresses the demand for each variety. We can now turn to firms' behavior.

\subsection{Firms' behavior}

The production of a typical variety involves a fixed cost, $f$, and a constant marginal cost, $a$, giving rise to economies of scale. The labor force required to produce this variety is then equal to:

$$
L=f+a q .
$$

Because each firm produces a distinct variety, the number of firms is also the number of varieties consumed. Thus each firm is a monopolist on the production of its varieties, and faces the demand function (8). But a key feature of the Dixit-Stiglitz monopolistic competition is that firms ignore the effects of their action on income $Y$, and on the price index $P$. Hence the demand curve as perceived by a typical firm 
is not (8), but rather: $q=b p^{-\sigma}$ where $b=\mu Y / P^{1-\sigma}$ is considered as a constant by each firm. According to this behavior, by maximizing the profit $\pi=p q-(f+a q) w$ a typical firm fixes the following price:

$$
p=\frac{a w \sigma}{\sigma-1}
$$

Because there is free entry, profits are always equal to zero, which, using eq.(10) and eq.(9), gives the level of output:

$$
\bar{q}=\frac{f(\sigma-1)}{a} .
$$

In equilibrium, a typical firm employs $f+a \bar{q}$ units of industrial entrepreneurs, so that the total demand is $n(f+a \bar{q})$, and using the level of output (11) and the fact that the total supply of labour is exactly $L$, the equalization gives the number of varieties produced:

$$
n=\frac{L}{\sigma f}
$$

The number of varieties produced is then proportional to the labour force $L$. This equation is important since it embodies increasing returns at the level of the firm, then a location with a large labour force produces a greater variety of goods than one with smaller labour input, and this labour input $L$ depends on the number of entrepreneurs and on commuting costs ( $L$ is given by eq.(2)).

\subsection{Transaction costs}

So far, the model has almost been described as a closed economy. The next step is to relax this assumption, trade occurring between the North, the South (denoted by $\left.{ }^{*}\right)$, and the rest of the world (denoted by ${ }^{\circ}$ ). Industrial varieties are exchanged between countries under transaction costs which take the form of iceberg costs: if an industrial variety produced in the Northern market is sold at price $p$ on it, then the delivered price (c.i.f) of that variety in the South (in the rest of the world) is going to be $\tau p\left(\tau^{\circ} p\right)$ with $\tau, \tau^{\circ}>1$.

The assumption of iceberg costs and the perceived elasticity of demand, $\sigma$, which is the same across regions implies that firms charge the same producer price in both regions, the distance does not imply 'discrimination', and 'mill pricing' is optimal. The first-order conditions for a typical firm's sales to its local market and to its export markets are:

$$
p=\frac{a w \sigma}{\sigma-1}, \quad p^{*}=\tau \frac{a w \sigma}{\sigma-1}, \quad p^{\circ}=\tau^{\circ} \frac{a w \sigma}{\sigma-1} .
$$

Krugman and Livas Elizondo [1996] assume that the input-output coefficient is equal to the reverse of the mark-up. This normalization simplifies prices which are equal 
to wages weighted by transaction costs. Furthermore the sum of the population (North+South) is normalized to one: $h+h^{*}=1$.

Iceberg costs also imply a modification of the price index (7). By using the above normalization we find:

$$
\begin{aligned}
P^{1-\sigma} & =n^{\circ} \phi^{\circ}\left(w^{\circ}\right)^{1-\sigma}+n w^{1-\sigma}+\phi n^{*}\left(w^{*}\right)^{1-\sigma}, \\
\left(P^{*}\right)^{1-\sigma} & =n^{\circ} \phi^{\circ}\left(w^{\circ}\right)^{1-\sigma}+\phi n w^{1-\sigma}+n^{*}\left(w^{*}\right)^{1-\sigma}, \\
\left(P^{\circ}\right)^{1-\sigma} & =n^{\circ}\left(w^{\circ}\right)^{1-\sigma}+\phi^{\circ} n w^{1-\sigma}+\phi^{\circ} n^{*}\left(w^{*}\right)^{1-\sigma},
\end{aligned}
$$

where $\phi^{\circ}, \phi$ represents a degree of trade freeness: $\phi^{\circ}=\left(\tau^{\circ}\right)^{1-\sigma}, \phi=(\tau)^{1-\sigma}$.

The price index in the North and in the South decreases with the size of the external market, and with international trade liberalization. Furthermore, at the symmetric equilibrium where wages are the same in North and South, an increase in $n$ and a decrease in $n^{*}$ implies, as long as there are transaction costs $(\phi<1)$, an increase in price index in the South and a decrease in price index in the North.

We now need to integrate transaction costs into the demand function. By considering the total demand as the sum of local demand and export demand, we find:

$$
q=\phi^{\circ} \frac{Y^{\circ}}{\left(P^{\circ}\right)^{1-\sigma}} p^{-\sigma}+\frac{Y}{P^{1-\sigma}} p^{-\sigma}+\phi \frac{Y^{*}}{\left(P^{*}\right)^{1-\sigma}} p^{-\sigma} .
$$

Ceteris paribus, the demand in the North is an increasing function of the income $Y^{\circ}$, and a decreasing function of the price index $P^{\circ}$. Obviously the higher the international trade liberalization, $\phi^{\circ}$, the higher the impact of the rest of the world on the northern demand. But considering the second and third terms we can notice that two opposite effects come from cities' size, indeed we have just seen that an increase

in the population in the North decreases $P$ and thus increases $P^{1-\sigma}$ and increases $P^{*}$ and thus decreases $\left(P^{*}\right)^{1-\sigma}$, then South-North migration fosters a decrease in the total demand $q$ in the North (if $\phi<1$ ). But what is the effect of a modification of location on income? A glance at the following equations will give an answer:

$$
\begin{aligned}
Y^{\circ} & =L^{\circ} w^{\circ}=h^{\circ}\left(1-\theta h^{\circ} / 2\right), \\
Y & =h(1-\theta h / 2) w, \\
Y^{*} & =h^{*}\left(1-\theta h^{*} / 2\right) w^{*} .
\end{aligned}
$$

An increase in $h$ in the North increases expenditure in this country and lowers it abroad, which causes as long as impediment to trade exists $(\phi<1)$, an increase in demand $q$.

\subsection{Market clearing condition and long term analysis.}

Thanks to these equations, we can now present the market clearing in a tidy form through an equalization of demand (eq.(17)) to supply (eq.(11)), prices are given by 
(10) which yields :

$$
\sigma f w^{\sigma}=\phi^{\circ} \frac{Y^{\circ}}{\left(P^{\circ}\right)^{1-\sigma}}+\frac{Y}{P^{1-\sigma}}+\phi \frac{Y^{*}}{\left(P^{*}\right)^{1-\sigma}} .
$$

Two opposite forces drive relative nominal wages : on the one hand an increase of entrepreneurs in one city exacerbates local competition among firms, thus new entry triggers a slump in the price index, and thereby in operating profits too, so that in order to stay in the market firms need to remunerate their workers less (market crowding effect). But on the other hand, as the income generated by the new entrepreneurs is spent locally, sales and operating profits increase and under the 'zero profit condition' this implies a higher nominal wage (the home market effect). However, entrepreneurs do not consider the relative nominal wage when they decide to migrate but the relative real wage. Hence in the long run migration stops when real wages are equalized in case of symmetry $\left(h=\frac{1}{2}\right)$, or when agglomeration in one city generates a higher relative real wage. More precisely it is assumed that migration is regulated by a simple marshallian adjustment:

$$
\dot{h}=\gamma_{h}\left(V(h, \cdot)-V^{*}(h, \cdot)\right),
$$

where $\gamma_{h}$ is the adjustment speed. Then by denoting $\Omega(h)$ the relative real wage, and defining it by:

$$
\begin{aligned}
\Omega(h, \cdot) & =\frac{V(h, \cdot)}{V^{*}(h, \cdot)} \\
& =\frac{w}{w^{*}} \frac{1-\theta h / 2}{1-\theta h^{*} / 2}\left(\frac{P^{*}}{P}\right),
\end{aligned}
$$

we will have a stable total agglomeration in the North if $\Omega(1, \cdot) \geqq 1$, and a stable dispersed equilibrium if $d \Omega(1 / 2, \cdot) / d h<0$. Notice that in the long run (eq.(23)) two additional forces appear, on the one hand the term $(1-\theta h / 2)$, which enters multiplicatively in the indirect utility, creates a dispersive force independently of transaction costs. This is the land market crowding effect ${ }^{5}$. On the other hand the third term $P^{*} / P$ is an agglomerative force. Indeed, we know that goods are cheaper in a central place because imports are lower and thus the burden of transaction costs too. Hence, entrepreneurs' purchasing power is higher in this location which attracts other entrepreneurs, this is the cost-linked circular causality also known as forward linkage.

\footnotetext{
${ }^{5}$ In the model, people commute to the CBD to work but not to consume, this is an important assumption since trade barriers do not affect the magnitude of the dispersion force (which is a knife-edge result that makes the analysis more tractable)
} 


\subsection{Critical points}

\subsubsection{When is the Core-Periphery pattern sustainable?}

The sustain point is the critical point of trade liberalization below which the CorePeriphery pattern is sustainable. To determine whether the agglomeration in the North is a stable equilibrium we need to know whether a small deviation of entrepreneurs from $h=1$ increases welfare or not. If it does, the Core-Periphery pattern is not a stable equilibrium. In the special case of autarky $\left(\phi^{\circ}=0\right)$, the sustain point is very easily found, indeed when $h=1$, price indexes are linked by the following equation:

$$
P=\phi^{1 /(\sigma-1)} P^{*}
$$

and wages by:

$$
w=\phi^{-1 / \sigma} w^{*} .
$$

Thus the relative indirect utility is given by:

$$
\Omega(1, \cdot)=\phi^{(2 \sigma-1) / \sigma(1-\sigma)}(1-\theta / 2),
$$

which shows that agglomeration is a stable equilibrium if and only if $\phi<\phi^{s}=$ $\left(1-\frac{\theta}{2}\right)^{\frac{\sigma(\sigma-1)}{2 \sigma-1}}$. Furthermore an increase in congestion costs $(\theta)$ and/or in the elasticity of substitution between varieties $(\sigma)$ decreases the level of regional integration at which the agglomeration is a stable equilibrium. ${ }^{6}$

This result has first been formulated by Krugman and Livas Elizondo [1996] and represents a new feature in the landscape of the NEG. Nevertheless, as these authors have pointed out, this sustain point which is calculated with $\phi^{\circ}=0$ is a very special case $^{7}$, and says nothing about what happens when the assumption of autarky with the rest of the world is relaxed. In fact, the introduction of the rest of the world implies a particular problem for the calculation of this critical point because price index and wages are no longer linked by a simple expression as in equations (24) and (25) but by a more complex and intractable expression ${ }^{8}$ which precludes the above simplification of the analysis. What we propose here is a calculation of this critical point by assuming that the rest of the world is as big as the total population in the

\footnotetext{
${ }^{6}$ Indeed from eq. (26) we have $\Omega(1, \cdot)=1$ for $\phi_{s}=\left(1-\frac{\theta}{2}\right)^{\frac{\sigma(\sigma-1)}{2 \sigma-1}}$ and $\Omega(1, \cdot)>1$ for $\phi<\phi_{s}$. Furthermore it is clear from $\phi^{s}=\left(1-\frac{\theta}{2}\right)^{\frac{\sigma(\sigma-1)}{2 \sigma-1}}$ that $\frac{\partial \phi_{s}}{\partial \sigma}<0$ and $\frac{\partial \phi_{s}}{\partial \theta}<0$.

7 "To consider how this model works, it is useful to consider what would happen if there are no foreign trade, and within that special case to ask only a limited question : under what conditions is concentration of all population in either location 1 and 2 an equilibrium?" Krugman and Livas [1996]

${ }^{8}$ Given by $P^{1-\sigma}=\frac{\left(P^{*}\right)^{1-\sigma}}{\phi}+L^{\circ} \phi^{\circ}\left(1-\frac{1}{\phi}\right)$ and $w^{\sigma}=\frac{\left(w^{*}\right)^{\sigma}}{\phi}+\frac{Y^{\circ}}{\left(P^{\circ}\right)^{1-\sigma}} \phi^{\circ}\left(1-\frac{1}{\phi}\right)$.
} 
North and South ${ }^{9}$, in other words $h^{\circ}=h+h^{*}=1$. This normalization implies that $w=1$ is a solution of the agglomerative equilibrium ${ }^{10}$, which permits to find the relative price index in a very simple form:

$$
\frac{P}{P^{*}}=\left(\frac{\phi^{\circ}+1}{\phi^{\circ}+\phi}\right)^{1 /(1-\sigma)} .
$$

Similarly the relative wage in the North is given by:

$$
\frac{w}{w^{*}}=\left(\frac{\phi^{\circ}+1}{\phi^{\circ}+\phi}\right)^{1 / \sigma}
$$

These two equations imply that the ratio of indirect utilities has the following form:

$$
\Omega(1, \cdot)=(1-\theta / 2)\left(\frac{\phi^{\circ}+\phi}{\phi^{\circ}+1}\right)^{\frac{2 \sigma-1}{\sigma(1-\sigma)}}
$$

which gives the following proposition:

Proposition 1 Agglomeration is a stable equilibrium if and only if $\phi<\phi^{s}=(1-$ $\left.\frac{\theta}{2}\right)^{\frac{\sigma(\sigma-1)}{2 \sigma-1}}\left(1+\phi^{\circ}\right)-\phi^{\circ}$. Furthermore international trade liberalization decreases the level of regional integration at which the agglomeration is a stable equilibrium.

Proof. From eq. $(29)$ we have $\Omega(1, \cdot)=1$ for $\phi_{s}=\left(1-\frac{\theta}{2}\right)^{\frac{\sigma(\sigma-1)}{2 \sigma-1}}\left(1+\phi^{\circ}\right)-\phi^{\circ}$ and $\Omega(1, \cdot)>1$ for $\phi<\phi_{s}$. Furthermore $\frac{\partial \phi_{s}}{\partial \phi^{\circ}}=\left(1-\frac{\theta}{2}\right)^{\sigma(\sigma-1) /(2 \sigma-1)}-1<0$ because $\theta<1$.

The reason why agglomeration is less likely when trade with the rest of the world is freer is the following: when regions trade more with the rest of the world, the benefit of agglomeration is reduced because a larger fraction of income is spent on goods that are imported and these goods have only one price in the North and in the South by assumption. Thus when an entrepreneur move from one city to the other the backward effect is dominated by the importance of the rest of the world, then when outlet becomes international the demand of the internal market and even the location in the domestic economy is less determining. After the sustain point, we can now turn to the break point.

\footnotetext{
${ }^{9}$ Three arguments can be put forward in order to justify this: first we work with monocentric cities, for those small cities the rest of world is often limited to the nearest big city, thus assuming that the latter entity is as large as the sum of the whole monocentric population is quite realistic. In fact if we consider that the big city is the first rank city, and monocentric cities are second-largest, our assumption follows Zipf's law at the dispersive equilibrium. Secondly this assumption is useful because it allows us to make an analysis in terms of external costs. Thirdly, this assumption is going to be relaxed in the next sections in order to understand more precisely how an increase in the world population could affect the equilibria.

${ }^{10}$ Indeed if $h=h^{\circ}=1$ then $n=n^{\circ}=\left(1-\frac{\theta}{2}\right) \frac{1}{\sigma f}$ and thus $P^{1-\sigma}=P^{\circ 1-\sigma}=\frac{1-\theta / 2}{\sigma f}\left(1+\phi^{\circ}\right)$ and with these price indices we can verify from (21) that $w=1$ is an equilibrium solution.
} 


\subsubsection{When is the symmetric equilibrium broken?}

The break point is the critical point of transaction costs above which the stability of the dispersive equilibrium is broken. To determine this point we need to evaluate the slope of $\Omega(h, \cdot)$ at the dispersive equilibrium. Then by totally differentiating the market clearing condition and the price index with respect to $h$, and by using the definition of real wages we find such a point (Appendix A gives the details of the computation) denoted $\phi_{b}$ which has the following implicit form:

$$
\phi_{b}: Z_{\phi}^{b}=\frac{\sigma(1-\sigma) \theta}{(\sigma-1)^{2} \theta-(2 \sigma-1)(4-2 \theta)},
$$

with:

$$
Z_{\phi}^{b}=\frac{1}{2}\left(\frac{w}{P}\right)^{1-\sigma}(1-\phi),
$$

where wage and price are given at the symmetric equilibrium by:

$$
\begin{aligned}
w & =\left[\phi^{\circ} \frac{Y^{\circ}}{\sigma f\left(P^{\circ}\right)^{1-\sigma}}+\frac{Y}{\sigma f P^{1-\sigma}}(1+\phi)\right]^{1 / \sigma}, \\
P & =\left[\left(L^{\circ} \phi^{\circ}\left(w^{\circ}\right)^{1-\sigma} / \sigma f\right)+\left(L w^{1-\sigma}(1+\phi) / \sigma f\right)\right]^{1 / 1-\sigma} .
\end{aligned}
$$

From these equations we can see that wage and price index are respectively decreasing and increasing with the size of the rest of the world and with international trade liberalization. This higher wage and smaller price index tend to decrease $Z_{\phi}$ which fosters the dispersive equilibrium (in the appendix we show that $\frac{\widehat{V(1 / 2, \cdot)}}{\widehat{h}}<0$ when $\left.Z_{\phi}<Z_{\phi}^{b}\right)$. Moreover an increase in commuting costs tends to break the agglomeration incentive. This can be summarized by the following proposition:

Proposition 2 An increase in the importance of the rest of the world $\left(\phi^{\circ}, L^{\circ}\right)$, or in commuting costs $(\theta)$, decreases the level of regional trade liberalization at which the stability of the dispersive equilibrium is broken.

Commuting costs $\theta$ play a role in this model that is comparable of the role of $\tau$ in other models: the lower the commuting costs, the more likely agglomeration will occur.

\subsection{Bifurcation diagram}

In order to get a full understanding of how the size of regions globally changes with trade liberalization, we make numerical simulations ${ }^{11}$ and get the so-called 'tomahawk diagram'. This diagram plots the location of entrepreneurs as a function of regional transaction costs.

\footnotetext{
${ }^{11}$ In this section parameters take the values $\sigma=5, \theta=0.4, h^{\circ}=3, \tau^{\circ}=1.5, f=1$
} 


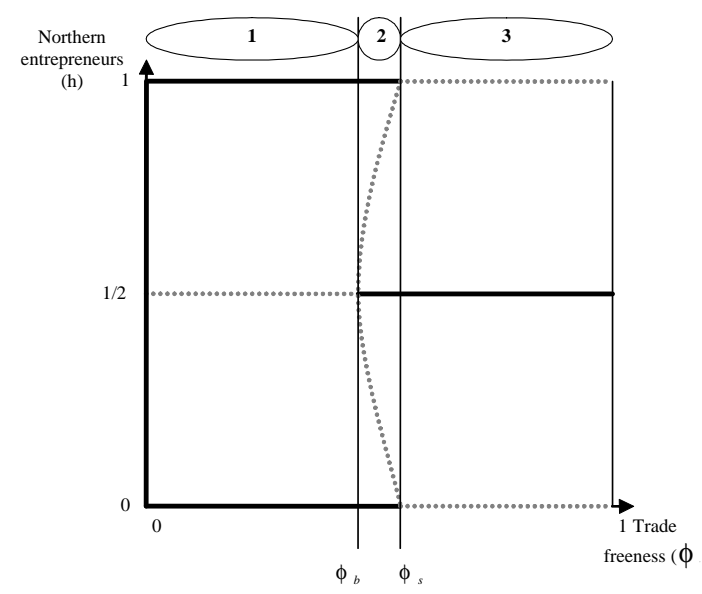

Figure 2: The tomahawk diagram

Three steps of trade liberalization are remarkable in Figure $2:$ in the first step of trade liberalization regions are in relative autarky, $\phi<\phi_{b}$ demand and cost linkage play an important role and all activities are localized in one of the two regions, agglomeration is then the only stable equilibrium. Indeed if we plot the welfare in each region as a function of the number of entrepreneurs in the North, as in Figure 3 , we clearly see that once a small deviation of entrepreneurs from the dispersive equilibrium occurs, further agglomeration is in the agents' interest because the relative indirect utility in the Core increases. Thus entrepreneurs decide to migrate because the relative welfare increases with their movement. However, if we compare their welfare at the symmetric equilibrium (in A) and at the agglomerated equilibrium (in $\mathrm{B}$ or $\mathrm{C}$ ), we can observe that they are worse off in this last situation. This simulation gives the following result: Dispersion Pareto dominates agglomeration.

This result is new ${ }^{12}$ and comes from the substitution of the immobile factor as the dispersive force with entrepreneurs' need to commute. Indeed on the contrary, in the Krugman [1991] model agglomeration Pareto dominates dispersion for entrepreneurs (this is proposition 3 of Charlot et al. [2006]). Here things are different, entrepreneurs prefer dispersion because this equilibrium allows them to reduce the burden of urban costs. However, due to the non linearity of the model, we cannot prove such a result for all $\phi^{\circ}$, however we make some other simulations in Appendix $\mathrm{B}$ in order to check the robustness of this conjecture. Moreover we can prove that :

Proposition 3 If regions are in autarky with the rest of the world, $\phi^{\circ}=0$, then whatever the level of regional transaction costs $\phi$, dispersion is a Pareto improvement for entrepreneurs.

\footnotetext{
${ }^{12}$ Notice however that in a different setting Gaigné [2006] also finds that dispersion can be a Pareto improvement.
} 
Proof. In autarky $\phi^{\circ}=0$, and at the dispersed equilibrium, $h=\frac{1}{2}$ price index are given by $P^{1-\sigma}=n w^{1-\sigma}(1+\phi)$ thus, by replacing $n$ by $\frac{L}{\sigma f}$ (see eq. (12)) and by using eq. (2) we get $P=\left(\frac{h(1-\theta h / 2)}{\sigma f}(1+\phi)\right)^{1 /(1-\sigma)} w$ thus indirect utility in the North which is given by $V\left(h, \phi^{\circ}, \cdot\right)=\frac{(1-\theta h / 2) w}{P}$ becomes equal to $V\left(\frac{1}{2}, 0, \cdot\right)=\left(\frac{1+\phi}{2 \sigma f}\right)^{1 /(\sigma-1)}(1-$ $\left.\frac{\theta}{4}\right)^{1+1 /(\sigma-1)}$. When all entrepreneurs are agglomerated in the North, $h=1$, the price index in this location is $P^{1-\sigma}=n w^{1-\sigma}$ thus we get $P=\left(\frac{h(1-\theta h / 2)}{\sigma f}\right)^{1 /(1-\sigma)} w$ and with this, entrepreneurs' indirect utility when they are agglomerated is given by $V(1,0, \cdot)=\left(\frac{1}{\sigma f}\right)^{1 /(\sigma-1)}\left(1-\frac{\theta}{2}\right)^{1+1 /(\sigma-1)}$. Then entrepreneurs prefer dispersion if

$$
\begin{aligned}
V\left(\frac{1}{2}, 0, \cdot\right) & >V(1,0, \cdot) \\
& \Leftrightarrow\left(\frac{1+\phi}{2 \sigma f}\right)^{1 /(\sigma-1)}\left(1-\frac{\theta}{4}\right)^{1+1 /(\sigma-1)}>\left(\frac{1}{\sigma f}\right)^{1 /(\sigma-1)}\left(1-\frac{\theta}{2}\right)^{1+1 /(\sigma-1)} \\
& \Leftrightarrow \phi>Z_{\theta}^{\sigma}-1 .
\end{aligned}
$$

since $Z_{\theta} \in\left[\frac{2}{3}, 1\right]$, the inequality $\phi>Z_{\theta}^{\sigma}-1$ is always verified, then entrepreneurs prefer dispersion for all $\phi$.

Such a proposition can be applied to the Murata and Thisse [2005]'s work since they use the Krugman and Livas model with $\phi^{\circ}=0$. Furthermore it is worth recalling that this result is obtained under the assumption that land rents accrue not to absentee landowners, but fully to residents, thus we are in a situation akin to a Prisoner's dilemma.

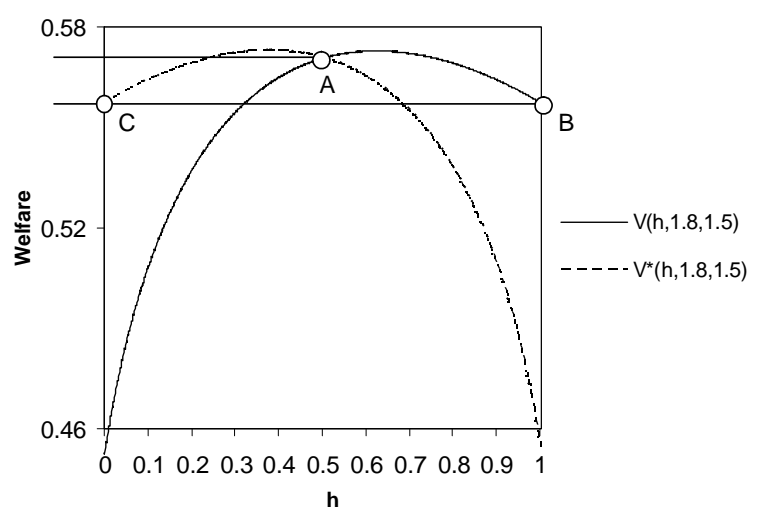

Figure 3: High trade costs

Coming back to Figure 2, we can see that in a second step of trade liberalization, between the break and sustain point, both the agglomeration and dispersion equilibria are stable. Indeed in Figure 4 at the dispersive equilibrium a small deviation from the South to the North makes the indirect utility higher in the South than in the North, thus entrepreneurs prefer to come back to the southern city. The dispersive equilibrium is stable in such a case. However if the migration shock is higher 
$(h>0.86)$, then they are strictly better off in the North, agglomeration occurs and becomes a stable equilibrium.

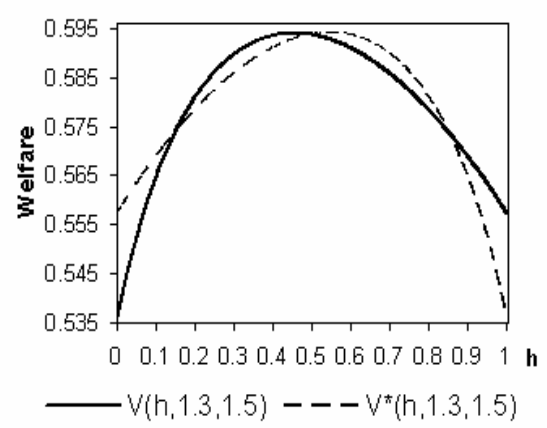

Figure 4: Intermediate trade costs

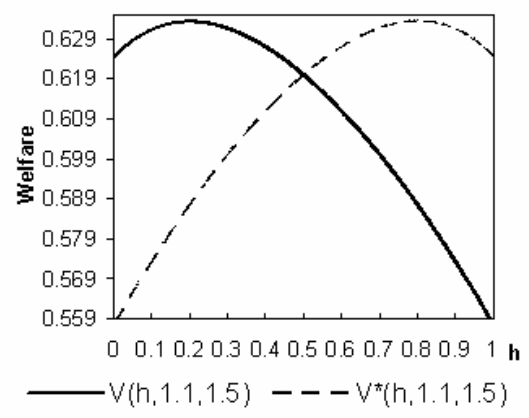

Figure 5: Low trade costs

The third step, characterized by strong trade liberalization $\phi>\phi_{s}$, displays an equal spread of activities among regions. Indeed in Figure 5 any deviations from the dispersive equilibrium cause a decrease in the welcoming city's welfare.

One of the most interesting features is that these two sorts of equilibrium - corner solutions in case of agglomeration, and an interior solution for location dispersion are also displayed by Krugman [1991]'s CP model, but not for the same transaction cost values. Indeed, in comparison with the initial Core-Periphery model, where dispersion appears before agglomeration, the situation is reversed here, but the symmetry between the two models does not come from a symmetric mechanism. Indeed, if everything was just reversed, the bell-shaped agglomeration rent, instead of being found near free-trade, would be obtained near autarky. The conclusion of race to the top for low transaction costs would then be found for high trade costs, and so on. But here the agglomeration rent is not bell-shaped. 


\subsection{Agglomeration rent}

Previous steps have shown that agglomeration forces are stronger when the rest of the world is relatively small and trade relatively restricted, the agglomeration rent is then the highest in this case, ceteris paribus entrepreneurs strictly prefer to be located in the North. The question is to know how this rent is influenced by trade liberalization between regions. The agglomeration rent is given by (29):

$$
\Omega(1, \cdot)=(1-\theta / 2)\left(1+\frac{1-\phi}{\phi^{\circ}+\phi}\right)^{\frac{2 \sigma-1}{\sigma(\sigma-1)}},
$$

which clearly gives the following result:

Proposition 4 Starting from a situation of agglomeration, an increase in trade liberalization (between regions or with the rest of the world) or an increase in commuting costs decreases the agglomeration rent.

Proof. we have:

$$
\begin{aligned}
\frac{\partial \Omega(1, \cdot)}{\partial \phi} & =-\frac{(1-\theta / 2)(2 \sigma-1)\left(\phi^{\circ}+1\right)}{\sigma(\sigma-1)\left(\phi^{\circ}+\phi\right)^{2}}\left(\frac{\phi^{\circ}+1}{\phi^{\circ}+\phi}\right)^{\frac{2 \sigma-1}{\sigma(\sigma-1)}-1}<0 \\
\frac{\partial \Omega(1, \cdot)}{\partial \phi^{\circ}} & =-\frac{(1-\theta / 2)(2 \sigma-1)(1-\phi)}{\sigma(\sigma-1)\left(\phi^{\circ}+\phi\right)^{2}}\left(\frac{\phi^{\circ}+1}{\phi^{\circ}+\phi}\right)^{\frac{2 \sigma-1}{\sigma(\sigma-1)}-1}<0 \\
\text { if } \theta & \neq 1 \text { and } \phi \neq 1 . \\
\frac{\partial \Omega(1, \cdot)}{\partial \theta} & =-\frac{1}{2}\left(1+\frac{1-\phi}{\phi^{\circ}+\phi}\right)^{\frac{2 \sigma-1}{\sigma(\sigma-1)}}<0 .
\end{aligned}
$$

In case of prohibitive costs between regions $\left(\phi, \phi^{\circ} \rightarrow 0\right)$, the agglomeration rent tends to infinity, in case of free trade $(\phi \rightarrow 1)$ this rent only depends on congestion costs. From a public policy point of view this decrease in the agglomeration rent is particularly interesting and very intuitive indeed as in the CP model, wage and price index in the North are constant, while $P^{* 1-\sigma}$ strictly decreases with $\phi$, thus the difference between the two models comes from entrepreneurs' wage in the South, in our model, this wage is strictly increasing in $\phi$ because a decrease in transaction costs allows one to have better access to the varieties produced in the Core. The real wage in the South is thus an increasing function of trade liberalization and because the reverse of this real wage determines the shape of the rent, this model displays a decreasing agglomeration rent. Moreover an increase in commuting costs $\theta$ erodes the agglomeration rent. Lastly, in order to see how this rent varies with the size of the external market we make some simulations ${ }^{13}$. In Figure 6 , the horizontal axis measures trade openness while the vertical axis measures agglomeration rent.

\footnotetext{
${ }^{13}$ Parameters take the values: $\phi^{\circ}=1, \theta=1, f=1, h=1$
} 


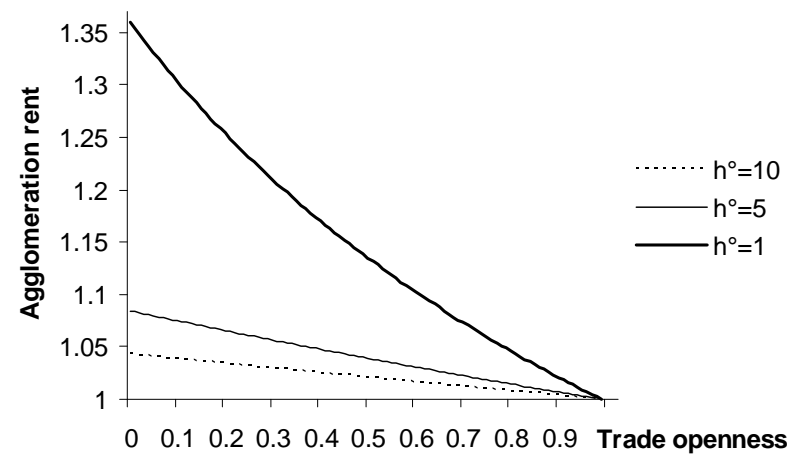

Figure 6: Agglomeration rent and growth of the rest of the world

In Figure 6 we can see that the population's growth in the rest of the world, $h^{\circ}$, decreases entrepreneurs' agglomeration rent. Indeed, when $h^{\circ}$ is high, the economy is outward oriented, the North is still the more attractive location on account of its larger market. However the backward linkage is weaker since a high proportion of firms' sales are now directed to the rest of the world. In other words, when international trade costs decrease it almost identical to meeting the external demand from anywhere, then the agglomeration rent decreases.

\section{Race to the bottom}

In this section we want to analyze the tax policies between governments in the case of a total agglomeration of activities, so we henceforth limit ourselves to $\phi<\phi_{b}$. Preferences are given by:

$$
U=M G,
$$

where $G$ is the consumption of local public goods. With Andersson and Forslid [2003], we assume that public goods are produced via private goods.

The amount of public good depends on taxation on income such as:

$$
G=t Y, \quad G^{*}=t^{*} Y^{*}
$$

and with the literature we assume that migration stops when post-tax reward is higher in the Core $^{14}$. The location equilibrium condition is thus given by:

$$
\frac{V}{V^{*}} \frac{1-t}{1-t^{*}} \geq 1
$$

\footnotetext{
${ }^{14}$ Another explanation of these equations can be proposed : we can assume that each jurisdiction supplies the same amount of public goods but with a financing of these goods $F$ and $F^{*}$ that can differ from one jurisdiction to the next, implicitly the efficiency of each government can be different (with $F=t Y, \quad F^{*}=t^{*} Y^{*}$ ). For a deeper analysis on the effect of bad governance on spatial choices see Candau (2008.b).
} 
Concerning the objective function of governments, we adopt the Borck and Pfluger [2006] modelling:

$$
\begin{aligned}
W & =G-t^{2} / 2 \text { with } G=t Y \\
W^{*} & =G^{*}-t^{* 2} / 2 \text { with } G^{*}=t^{*} Y^{*}
\end{aligned}
$$

Notice that the objective function in the Periphery is negative and decreasing with the tax rate (if the South (North) is the Periphery then $Y^{*}=0(Y=0)$ and thus $\left.G^{*}=0(G=0)\right)$. This can be interpreted by the fact that the South has a higher predator behavior than the North ${ }^{15}$. The local governments play a Stackelberg game, the sequence of this game is the following:

1. The North, which is assumed to be the Core ${ }^{16}$ and then the leader of Stackelberg, sets a tax rate $t$.

2. The South, which is the Periphery and the follower reacts through a tax rate $t^{*}$.

\section{Lastly, migration occurs.}

This game is resolved by backward induction. The third stage is already known by the previous analysis of the model. Concerning the second stage, whatever the decision of the Core concerning the level of taxation, the Periphery has almost always an incentive to steal all the activities, at most it can be indifferent. Figure 7 illustrates this. The vertical axis represents the objective function of the South, while the horizontal axis plots the level of taxation in this country.

There are two possible situations, if the South does not succeed in stealing the Core, then its revenue is going to be null, and its objective function is negative, on the contrary, if this country succeeds in attracting all the activities, then its revenue is going to be equal to $t^{*} Y^{*}$, and its objective function becomes bell-shaped. Total agglomeration in the North depends therefore on the potential taxation levied by the South. The Northern government can indeed be upset by a tax $t_{b}^{*}$, which enables the South to break the Core equilibrium:

$$
t_{b}^{*}=1-\Omega(1, \cdot)(1-t)
$$

This break-point tax rate rises with $t$ and falls with $\Omega(1, \cdot)$.

\footnotetext{
${ }^{15}$ We can imagine, for instance, that it is marginally more interesting for a small country to attact some activities than for a big one.

${ }^{16}$ The reverse can obviously be assumed.
} 


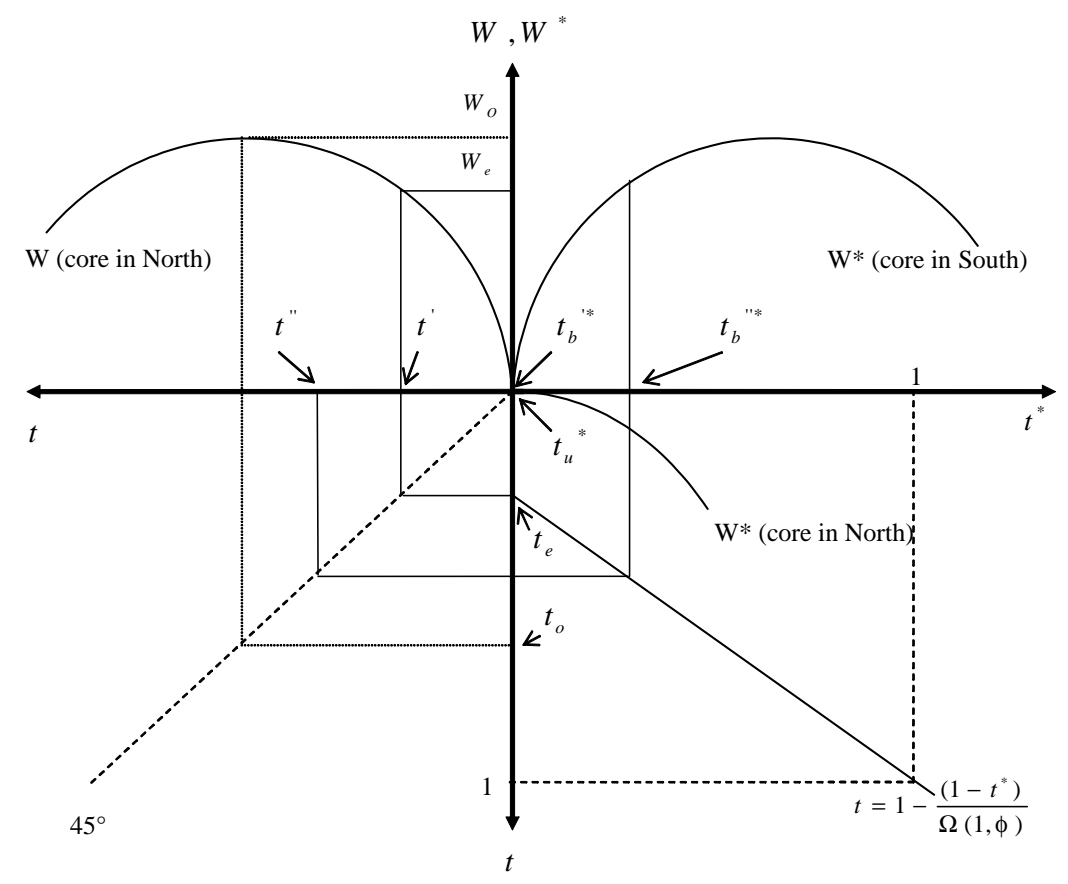

Figure 7: The tax game

Thus if we start from a situation where the Core/North sets a high tax rate, say $t^{\prime \prime}$, then the break-point tax rate, denoted $t_{b}^{\prime \prime *}$ on the diagram is also high, and thus the South can steal the Core by setting $t^{*}$ equal to $t_{b}^{\prime \prime *}$. If the North decides to choose a lower level of taxes, say $t^{\prime}$, then in such a case the South can steal the Core by lowering $t^{*}$ to $t_{b}^{\prime *}$. However in such a case $t_{b}^{*}$ is equal to zero, and thus equivalent to the tax rate that maximizes the objective function of the South without the Core, namely $t_{u}^{*}$, thus the South is indifferent between the Core or the Periphery. Therefore, in the first stage, if the North wants to keep the Core, it needs to set a tax below or equal to $t^{\prime}$, such that the South does not want to deviate from $t_{u}^{*}=t_{b}^{\prime *}$. This limit tax rate, denoted $t_{e}$, is thus equal to $t^{\prime}$ on the diagram and analytically found by:

$$
\begin{aligned}
t & \leq t_{e}=1-\frac{1-t_{b}^{*}}{\Omega(1, \cdot)} \\
\text { where } t_{b}^{*} \text { s.t } W^{*}\left[t_{u}^{*} Y^{*}(0, \cdot), t_{u}^{*}\right] & =W^{*}\left[t_{b}^{*} Y^{*}(1, \cdot), t_{b}^{*}\right] .
\end{aligned}
$$

We now need to verify that the North always prefers to have the Core. This is demonstrated by the fact that the North wins $W_{e}$ with the Core and nothing without, accordingly the North will always "limit tax" the South. 


\subsection{Equilibrium tax gap}

From the previous analysis we know that $t_{b}^{*}=0$ (see Figure 7 ) then we get:

$$
t_{e}=1-\frac{1}{\Omega(1, \cdot)}
$$

furthermore we know that $t_{u}^{*}=0$ thus the tax gap $\left(t_{e}-t_{u}^{*}\right)$ only depends on $t_{e}$ which decreases when $\Omega(1)$ decreases. Since it has been found in Proposition 4 that $\Omega(1)$ decreases with $\phi, \phi^{\circ}$ and $\theta$ we can present the following proposition:

Proposition 5 International trade liberalization $\left(\phi^{\circ}\right)$ as well as regional integration $(\phi)$ leads to a race to the bottom in terms of taxation. On the contrary, a reduction in commuting costs leads to a race to the top.

Proof. We have:

$$
\begin{aligned}
\frac{\partial\left(t_{e}-t_{u}^{*}\right)}{\partial \phi} & =\frac{1}{\Omega(1, \cdot)^{2}} \frac{\partial \Omega(1, \cdot)}{\partial \phi} \\
\frac{\partial\left(t_{e}-t_{u}^{*}\right)}{\partial \phi^{\circ}} & =\frac{1}{\Omega(1, \cdot)^{2}} \frac{\partial \Omega(1, \cdot)}{\partial \phi^{\circ}} \\
\frac{\partial\left(t_{e}-t_{u}^{*}\right)}{\partial \theta} & =\frac{1}{\Omega(1, \cdot)^{2}} \frac{\partial \Omega(1, \cdot)}{\partial \theta}
\end{aligned}
$$

and we know from Proposition 4 that $\frac{\partial \Omega(1, \cdot)}{\partial \phi^{\circ}}<0$ so $\frac{\partial\left(t_{e}-t_{u}^{*}\right)}{\partial \phi^{\circ}}<0$, similarly from the same proposition $\frac{\partial \Omega(1, \cdot)}{\partial \phi}<0$ so $\frac{\partial\left(t_{e}-t_{u}^{*}\right)}{\partial \phi}<0$, and $\frac{\partial \Omega(1, \cdot)}{\partial \theta}<0$ thus $\frac{\partial\left(t_{e}-t_{u}^{*}\right)}{\partial \theta}<0$.

This proposition is new for three reasons, at first the NEG literature which treats of the entrepreneurs mobility concludes that the government which hosts the core of activities can increase its taxation without capital flight in the first step of regional trade liberalization, which is never the case here, secondly in contrast with the literature which only considers tax competition of cross border regions when trade between these regions is liberalized, here we have analyzed the impact of international integration on regional tax competition, that link is both relevant and important for circles that are not just academic and certainly deserves to be tested in other models with multi-regions. Such a work is done in the last section. Lastly the effect of urban costs on tax competition has not been analyzed so far.

\section{$3.2 \quad$ Asymmetric cities}

A drawback of our analysis is that we consider tax competition only under the case of total agglomeration. This choice has been done because the study of the dispersive equilibrium is not very interesting since we find the same result than the BTCM 
(and to Andersson and Forslid [2003] or Ludema and Wooton [2000]) : a small tax differential leads to a small relocation of the mobile factor. However an extension that can be instructive is to check the previous result of a race to the bottom in the case where two stable asymmetric equilibria emerge. The problem is that our model displays a 'subcritical pitchfork bifurcation' which means that this situation never happens (see Figure 2), but this kind of bifurcation depends on the modelling of the centrifugal force, then we simply need to change this modelling in order to obtain a 'supercritical pitchfork bifurcation' where two asymmetric equilibria emerge. Instead of using the explicit treatment of land rent and commuting costs carried out in section 1 , we are going to simplify the analysis by integrating ad-hoc congestion costs à la Fujita, Krugman and Venables [1999, chapter 18]: now the relationship between individual welfare and commuting costs takes the following non linear form $V(h, \cdot)=(1-L)^{\theta} \frac{w}{P}$ where $L$ does not represent the labour force as before but the number of entrepreneurs in the North. Then the relative real wage which determines migration becomes equal to:

$$
\Omega(L, \cdot)=\frac{w}{w^{*}} \frac{(1-L)^{\theta}}{\left(1-L^{*}\right)^{\theta}}\left(\frac{P^{*}}{P}\right)
$$

where $(1-L)^{\theta}$ and $\left(1-L^{*}\right)^{\theta}$ represent congestion costs in North and South. Thanks to this, the first remark that can be done is that there is never a total agglomeration in this model (and thus no agglomeration rent), indeed imagine that every entrepreneurs are agglomerated in the North, then in such a case the term $(1-L)^{\theta}$ becomes equal to zero thus the term $\Omega(1, \cdot)$ also, and we know that agglomeration in North is impossible when $\Omega(1, \cdot)<1$. In other words, when there is many people in the same location, congestion costs are very high, which makes the total agglomeration impossible.

All other equations remain identical of those presented in section 1, excepted nominal incomes, indeed entrepreneurs do not commute and do not receive land rent, thus equations (18), (19) and (20) become equal to:

$$
Y^{\circ}=L^{\circ} w^{\circ}, \quad Y=L w, \quad Y^{*}=L^{*} w^{*} .
$$

In order to get a full understanding of how the size of regions globally changes, we make numerical simulations and obtain the so-called 'wiggle and tomahawk diagram'. The wiggle diagram plots the relative real wages in the North as a function of the number of entrepreneurs located in this country. Concerning low trade costs, results are similar of what we have studied until now (there is dispersion), and thus in Figure 10 we only plot three cases of high trade costs. 


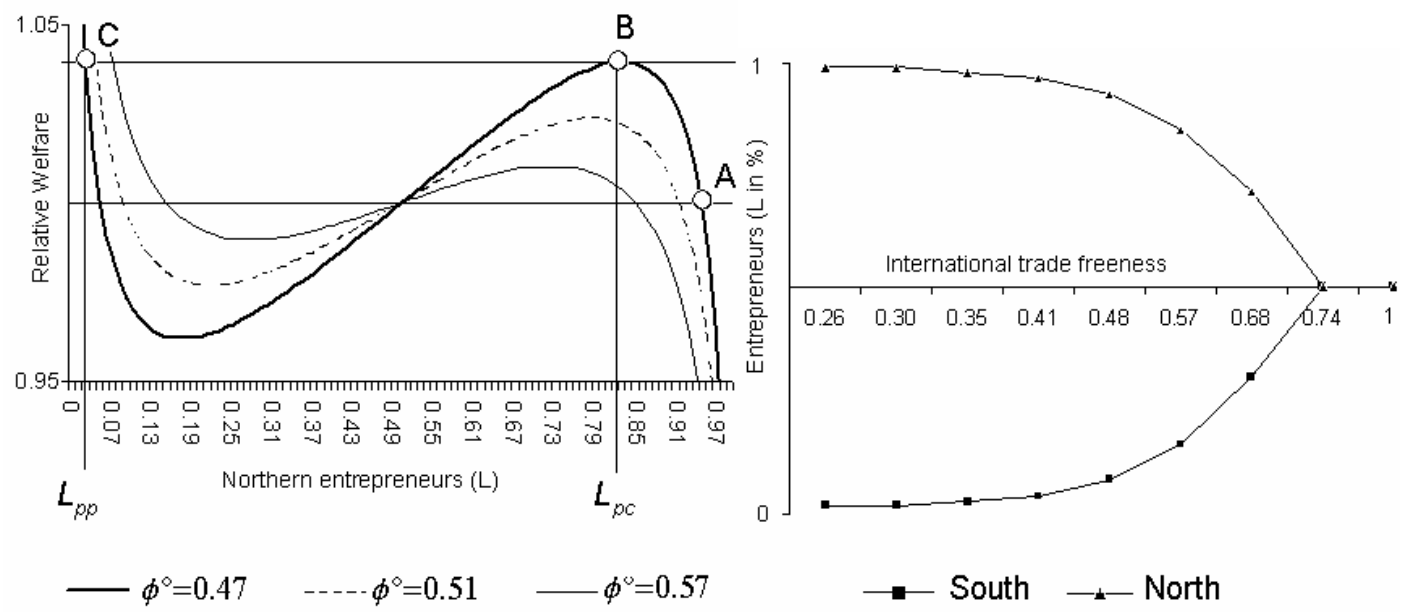

Figure 8 : The wiggle diagram

Figure 9 : The tomahawk diagram

The model develops an interesting and new feature because there is neither a total dispersion, nor a total agglomeration but an intermediate case of partial agglomeration. As we can see in Figure 8, for instance concerning the dashed line, the relative real wage crosses the horizontal line three times, indicating that there are three interior equilibria, whose sole extremes are stable. Indeed at $L=1 / 2$, the relative real wage has a positive slope, which means that a south-to-north migration (or the reverse) is interesting for entrepreneurs, but this interest stops before agglomeration becomes total, indeed approximately after $L=0.9$, the welfare is higher in the South than in the North, which makes the partial agglomeration stable. With such a setting we find the supercritical pitchfork bifurcation illustrates by Figure 9 : trade liberalization leads gradually activities from partial agglomeration to dispersion.

In contrast to the previous analysis, the partial agglomeration does not generate an agglomeration rent (indeed the partial agglomeration equilibrium is defined by $\left.\Omega\left(L, \phi, \phi^{\circ}\right)=1\right)$, which means that now a tax differential will imply some relocations. Such relocations are interesting for the North, since its payoff and the relative welfare of its residents increase with a partial loss of firms (in Figure 8, from the situation A to the situation B). This implies that in determining the equilibrium of the tax game we cannot impose $L=1$ rather the equilibrium of the tax game determines the North and the South tax rate and the number of entrepreneurs in the two countries simultaneously. Once again we applied the Stackelberg game ${ }^{17}$. As explained in BP, in the second stage the South has two choices, it can set a tax $t_{b}^{*}$ in order to steal the

\footnotetext{
${ }^{17}$ The simultaneous Nash equilibrium does not exist in this case of partial agglomeration.
} 
partial core (the partial core is represented by $L_{p c}$ when $\phi^{\circ}=0.48$ on the diagram $8)$ or it can set a tax $t_{u}^{*}$ in order to maximize its partial periphery income $\left(L_{p p}\right.$ when $\phi^{\circ}=0.48$ on the diagram 8). Then if the North wants to keep the partial core, it needs, in the first stage, to set a tax such that the South does not want to deviate from $t_{u}^{*}=t_{b}^{*}$. This limit tax rate, denoted $t_{e}$, is given by:

$$
\begin{aligned}
t & \leq t_{e}=1-\frac{1-t_{b}^{*}}{\Omega\left(L_{p c}, \cdot\right)} \\
\text { where } t_{b}^{*} \text { s.t } W^{*}\left[t_{u}^{*} Y^{*}\left(L_{p p}^{*}, \cdot\right), t_{u}^{*}\right] & =W^{*}\left[t_{b}^{*} Y^{*}\left(L_{p c}^{*}, \cdot\right), t_{b}^{*}\right] .
\end{aligned}
$$

Because it is not possible to obtain closed-form solutions we turn to numerical simulations in order to illustrate the tax gap $t_{e}-t_{u}^{*}$.

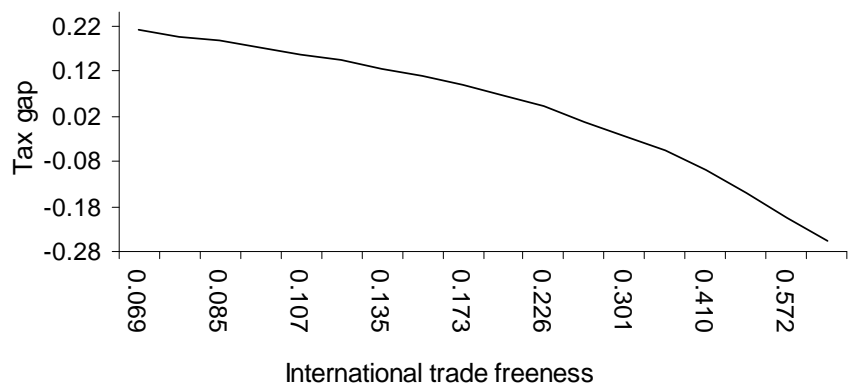

Figure 10 : Partial agglomeration and tax gap

In Figure 10, the vertical axis represents the tax gap, and the horizontal axis the international trade freeness. This Figure displays a result that is exactly the reverse of what has been found by Borck and Pflüger [2006], BP for short, indeed while these authors find that a decrease in trade freeness implies that the tax differential falls, we find that this tax gap decreases when trade is liberalized. Thus while BP indicate that their findings generalize the race to the top result of the core-periphery model, we conclude that in a model where the dispersive force of immobile farmers is replaced by congesting costs then a race to the bottom emerges. This change of conclusion simply comes from the fact that in our model an increase in trade freeness exacerbates dispersion forces and then limits the capacity of the Northern government to impose an important tax gap, and then around the dispersive equilibrium this government needs to set a smaller tax rate than its opponent in order to keep the partial core, this is the reason why even with positive taxes, the tax gap can be negative since $t_{e}<t_{u}^{*}$.

Proposition 6 International trade liberalization leads to a race to the bottom in terms of taxation over the range where partial agglomeration is stable ${ }^{18}$.

\footnotetext{
${ }^{18}$ Parameters used are the following $\sigma=5, \phi=1.8, f=1, \theta=0.1$. In appendix $\mathrm{C}$ we make numerous robustness checks (which are not done in $\mathrm{BP}$ ) in order to be sure that the result we plot and report is representative.
} 
This result can also be understood in another way, indeed since the decrease in $\phi^{\circ}$ makes cities less asymmetric, we can remark that the tax gap is higher for countries that strongly differs in size than between countries that are comparable in theirs rate of urbanization. This leads to the conclusion that a positive link exists between tax competition and the degree of similarity in urbanization rates.

Lastly in order to link the present analysis with the literature, we want to notice that since the presence of immobile farmers is central at a regional or at a national scale, while the presence of congesting costs is perhaps more relevant at the cities scale, therefore the result of BP may indicate that a race to the top can emerge between asymmetric nations, while in accordance with our result, a race to the bottom may arise between cities. Thus with Fujita and Thisse [2001] we can conclude that "what is true at a certain spatial scale is not necessarily true at another (the "ecological fallacy")" and thus a decentralization policy may not be based on the ground of what we know about national tax interactions.

\section{More investigations on tax competition and in- ternational trade}

\subsection{A multi-regions model}

In order to test the robustness of our result concerning the impact of international trade liberalization on tax competition we are going to integrate tax competition in the model of Monfort and Nicolini $(2000)^{19}$. This model is a competing framework of Krugman and Livas in the sense that international trade liberalization makes intranational agglomeration more likely which is the reverse of Proposition 2 presented here. These authors present a multi-regions economy, two countries (subscript 1 and 2 ) and two regions in each country (no superscript for northern regions of country 1 and 2 , and "*" for southern regions), with no commuting costs and no land rent and where the dispersive force comes from the presence of immobile agricultural workers (denoted $L_{a}$ while $L$ represents the number of entrepreneurs). Regional mobility of entrepreneurs is assumed but there is no international migration. Then we analyse regional tax competition inside countries (the northern government in country $i=1,2$ sets a tax $t_{i}$ on nominal incomes, while the southern government sets a tax $t_{i}^{*}$ ). Trade freeness inside each country is identical and denoted $\phi$ and international trade freeness is denoted $\phi^{\circ}$. Consumption gives the following utility of the representative consumer: $U=M^{\mu} A^{1-\mu}$ with $\mu$ the preference for the industrial good. Concerning the industrial sector, equations remain identical of those

\footnotetext{
${ }^{19} \mathrm{I}$ am grateful to one of the two referees for pointing Monfort and Nicolini (2000) out to me.
} 
presented in section 1 . Concerning the agricultural sector, goods are produced under perfect competition and there is no trade costs on these products. Wage in this sector is taken as the numeraire and normalized at one. Lastly authors consider that the population of each country is also normalized at 1 , of which a fraction $1-\mu$ are immobile agricultural and $\mu$ are manufacturing workers. Since we are interested by tax competition between asymmetric regions we consider only the case where in both countries, the manufacturing industry is entirely located in one region. ${ }^{20}$ Furthermore, we assume that governments have the same objective function in country 1 and 2 which allows to focus our attention on tax competition between regions inside one country (thus the absence of subscripts that refer to countries denotes that we work indifferently with country 1 or 2$)$. Because there is now two tax payers the objective function is still given by (31) but with $G=t\left(L w+L_{a} w_{a}\right)$ and $G^{*}=t^{*}\left(L^{*} w^{*}+L_{a}^{*} w_{a}\right)$. To avoid intractable interactions, we will assume with Andersson and Forslid [2004] that the public good is produced by means of the average consumption basket; i.e., a fraction $1-\mu$ of the tax revenue is spent on agricultural goods, and a fraction $\mu$ on manufactures. ${ }^{21}$ An implication of this is that all the variables obtained by Monfort and Nicolini [2000] such as wages and prices are independent of taxes. Then the agglomeration rent obtained (see Monfort and Nicolini (2000, p301, eq. 14) is given by:

$$
\Omega(1, \cdot)=2 c^{\sigma \mu /(1-\sigma)}\left[(1+\mu) c+(1-\mu) c^{-1}\right]^{-1}
$$

with $c=\frac{\phi^{\circ}+\phi}{1+\phi^{\circ}}$. Observe that $\Omega(1, \cdot)$ can be bell-shaped with respect to the freeness of trade, indeed a $\log$ differentiation of $\Omega(1, \cdot)$ gives:

$$
\frac{d \Omega(1, \cdot) / \Omega(1, \cdot)}{d c / c}=\frac{\sigma-1-\mu \sigma-c^{2}(1+\mu)(\sigma-1+\mu \sigma)}{(1-\mu)^{-1}\left(1-\mu+c^{2}(1+\mu)\right)(-1+\sigma)}
$$

and thus if $\sigma>\frac{1}{1-\mu}$ the first right-hand term can be positive and since the second term is increasing in $c$ and is zero at $c=0$, the derivative is clearly positive up to some critical value of $c$ and after this it is negative. Solving $\frac{\partial \Omega(1, \cdot) / \Omega(1, \cdot)}{\partial c / c}=0$, the top of the bell is at $c=\sqrt{\frac{(1-\mu)(1+\sigma(\mu-1))}{(1+\mu)(1-\sigma(\mu+1))}}$. Moreover we can observe that for a high value of $c$, the agglomeration rent is strictly decreasing, indeed if $c>\sqrt{\frac{\sigma-1-\mu \sigma}{(1+\mu)(\sigma-1+\mu \sigma)}}$ then $\frac{d \Omega(1, \cdot) / \Omega(1, \cdot)}{d c / c}<0$. Since $c=\frac{\phi^{\circ}+\phi}{1+\phi^{\circ}}$ this conclusion can be reformulated as follows: the bell-shaped agglomeration rent that occurs with regional trade integration, becomes strictly decreasing when international trade is free enough, i.e. if

\footnotetext{
${ }^{20}$ Obviously the richness of this model allows to analyse other cases, but this is left for future research.

${ }^{21}$ See Baldwin et al. [2004, p. 404] for a justification of this assumption based on the median voters.
} 
$\phi^{\circ}>\frac{\sqrt{\frac{\sigma-1-\mu \sigma}{(1+\mu)(\sigma-1+\mu \sigma)}-\phi}}{1-\sqrt{\frac{\sigma-1-\mu \sigma}{(1+\mu)(\sigma-1+\mu \sigma)}}}$. As the following result shows, such a conclusion has some implications in terms of tax competition.

Proposition 7 In a multi-regions model, a race to the bottom occurs with regional integration $(\phi)$ if and only if international trade is free enough $\left(\phi^{\circ}>\frac{\sqrt{\frac{\sigma-1-\mu \sigma}{(1+\mu)(\sigma-1+\mu \sigma)}}-\phi}{1-\sqrt{\frac{\sigma-1-\mu \sigma}{(1+\mu)(\sigma-1+\mu \sigma)}}}\right)$. As a corollary if local trade is free enough $\left(\phi>\left(\phi^{\circ}-1\right) \sqrt{\frac{\sigma-1-\mu \sigma}{(1+\mu)(\sigma-1+\mu \sigma)}}-\phi^{\circ}\right)$, a race to the bottom is also generated by the process of international trade integration.

Proof. From the above normalization $\left(L_{a}=\frac{1-\mu}{2}, L=\frac{\mu}{2}\right.$ and $\left.w_{a}=1\right)$, it is easy to find the northern income with the core: under this scheme authors find $w=1$ and thus get $Y_{c}=\frac{1}{2}$. Similarly at the Periphery one can find: $Y_{p}^{*}=\frac{1-\mu}{2}$ (because there is only immobile workers). As previously the Stackelberg game is resolved by backward induction. In the last stage, the North has won the Core, thus the national income of the South only consists of the earning of immobile workers and the objective function of this peripheral region $\left(W_{p}^{*}\right)$ is:

$$
W_{p}^{*}=t^{*} Y_{p}^{*}-\frac{t^{* 2}}{2}
$$

By maximizing this with respect to $t^{*}$, the periphery sets $t^{*}=Y_{p}^{*}=\frac{1-\mu}{2}$ denoted $t_{u}^{*}$ hereafter. With such a tax rate, the South gets $W_{p}^{*}=\frac{(1-\mu)^{2}}{8}$. This tax rate has been chosen by the South because in the previous sequence of the game the North has chosen the level of $t$ that makes the South indifferent between being the Core or the Periphery. This indifference is given by $W_{p}^{*}=W_{c}^{*}$ which is equivalent to $\frac{(1-\mu)^{2}}{8}=t^{*} Y_{c}^{*}-\frac{t^{* 2}}{2}$ and finally gives $t^{*}=\frac{1-\sqrt{\mu(2-\mu)}}{2}$ denoted $t_{b}^{*}$. The North has limited the South incentive to attract activities by setting $t=1-\left(\left(1-t_{b}^{*}\right) / \Omega(1, \cdot)\right)$ denoted $t_{e}$. Then, by using the expression of $t_{b}^{*}$ we get $t_{e}=1-\frac{1+\sqrt{\mu(2-\mu)}}{2 \Omega(1, \cdot)}$ which allows to analyse the following expression:

$$
\frac{\partial t_{e}}{\partial c}=\frac{1+\sqrt{\mu(2-\mu)}}{2 \Omega(1, \cdot)^{2}} \frac{\partial \Omega(1, \cdot)}{\partial c}
$$

Since we have already shown that $\frac{\partial \Omega(1, \cdot)}{\partial c}<0$ if $\phi^{\circ}>\frac{\sqrt{\frac{\sigma-1-\mu \sigma}{(1+\mu)(\sigma-1+\mu \sigma)}}-\phi}{1-\sqrt{\frac{\sigma-1-\mu \sigma}{(1+\mu)(\sigma-1+\mu \sigma)}}}$, and because $\frac{\partial c}{\partial \phi}=\frac{1}{1+\phi^{\circ}}>0$ we can conclude that $\frac{\partial t_{e}}{\partial \phi}<0$ thus $\frac{\partial\left(t_{e}-t_{u}^{*}\right)}{\partial \phi}<0$ (indeed $t_{u}^{*}=\frac{1-\mu}{2}$ ) which means that if international trade is free enough $\left(\phi^{\circ}>\frac{\sqrt{\frac{\sigma-1-\mu \sigma}{(1+\mu)(\sigma-1+\mu \sigma)}}-\phi}{1-\sqrt{\frac{\sigma-1-\mu \sigma}{(1+\mu)(\sigma-1+\mu \sigma)}}}\right)$ then a race to the bottom occurs with regional trade integration. Lastly by noting that the 
condition $\phi^{\circ}>\frac{\sqrt{\frac{\sigma-1-\mu \sigma}{(1+\mu)(\sigma-1+\mu \sigma)}}-\phi}{1-\sqrt{\frac{\sigma-1-\mu \sigma}{(1+\mu)(\sigma-1+\mu \sigma)}}}$ can be rewritten $\phi>\left(\phi^{\circ}-1\right) \sqrt{\frac{\sigma-1-\mu \sigma}{(1+\mu)(\sigma-1+\mu \sigma)}}-\phi^{\circ}$ and by observing that $\frac{\partial c}{\partial \phi^{\circ}}=\frac{1-\phi}{\left(1+\phi^{\circ}\right)^{2}}>0$ we can conclude that $\frac{\partial\left(t_{e}-t_{p}^{*}\right)}{\partial \phi^{\circ}}<0$. Thus if local trade is free enough $\left(\phi>\left(\phi^{\circ}-1\right) \sqrt{\frac{\sigma-1-\mu \sigma}{(1+\mu)(\sigma-1+\mu \sigma)}}-\phi^{\circ}\right)$, a race to the bottom is generated by the process of international trade integration.

To illustrate this proof, some simulations of the tax gap $t_{e}-t_{u}^{*}$ with respect to local trade freeness are done in Figure $11^{22}$, and show how the degree of international trade affects the local tax competition. When international trade freeness is low $\left(\phi^{\circ}=0.1\right)$ the bell-shaped configuration obtained in Baldwin and Krugman (2004, Figure 6$)$ is verified, however for an higher level of openness $\left(\phi^{\circ}=0.6\right)$, local trade integration generates a race to the bottom.

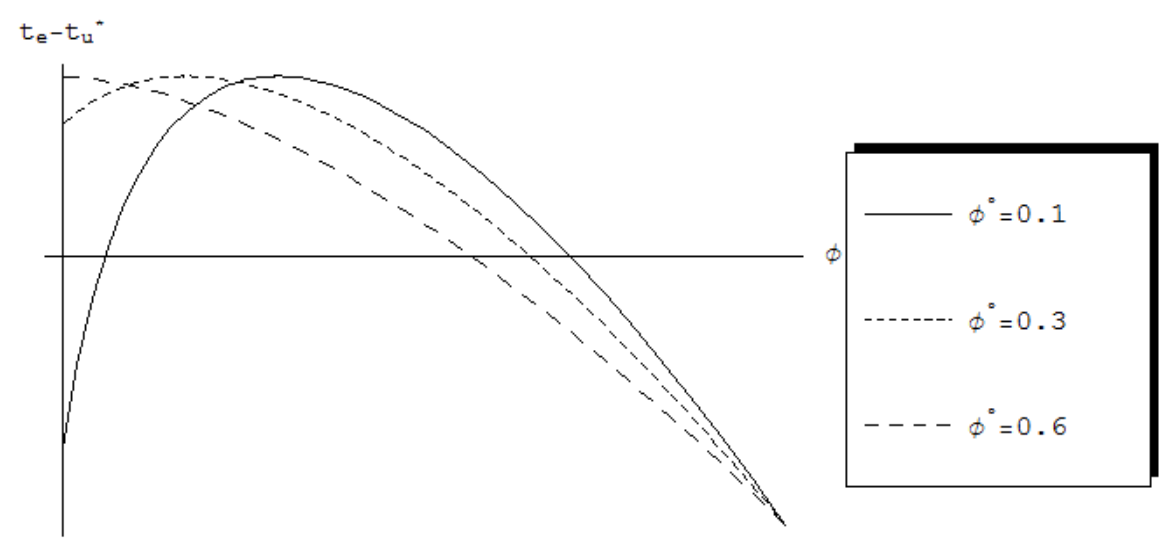

Figure 11

\subsection{Tax harmonization}

The model of Monfort and Nicolini [2000] with local governments can be used to examine tax harmonization and more precisely to analyse the proposition made by BK about a weakly Pareto improvement brought by a southern tax floor. In this model as well as in the BK case, there are two tax payers, entrepreneurs and immobile workers, thus the objective function in the Periphery (denoted $W^{*}$ ) is an unversed U-curve of $t^{*}$, even if there are no entrepreneurs in this country because the government gets revenue from the immobile workers. The unconstraint tax in the Periphery, $t_{u}^{*}$ in Figure 12, is thus positive, and a tax floor set at this southern tax rate relaxes a part of the northern constraint, which can attain the welfare $W_{u}^{\prime}$ by increasing its tax from $t_{e}^{\prime}$ to $t_{u}^{\prime}$. That analysis thus confirms the result of BK, but we want to check its robustness by asking the following question: What happen if the government does not tax the immobile factor? This question is particularly

\footnotetext{
${ }^{22}$ Parameters: $\sigma=4, \mu=0.4$
} 
relevant in the case where different levels of governments are specialized in term of taxation, for instance in France $45 \%$ of cities are under a scheme of cooperation where the interjuridictionals levels can only tax the mobile factor (via the "Taxe Professionnelle Unique". There is 1161 interjuridictionals levels and 40,9 millions of people live under this scheme in 2006). Furthermore such a question concerning the number of tax instruments available is usual in the traditional literature on tax competition (Wellisch [2000] for an overview).

Notice that Borck and Pflüger [2006], BP for short, analyse tax competition under this assumption however these authors have failed to account for tax harmonization and this section can thus be understood as complementary to their work. The current model predicts the following result :

Proposition 8 If the tax-game only concerns the mobile factor then a tax floor scheme for the Periphery is detrimental for this region.

Proof. If regional governments do not get revenue from the immobile workers i.e if the objective function is for instance given by:

$$
\begin{aligned}
W & =G-t^{2} / 2 \text { with } G=t L w \\
W^{*} & =G^{*}-t^{* 2} / 2 \text { with } G^{*}=t^{*} L^{*} w^{*}
\end{aligned}
$$

then the objective function in the Periphery is not longer an unversed U-curve of $t^{*}$, this objective function, denoted $W^{\prime \prime *}$ in Figure 12, shifts downward and then $t_{u}^{\prime *}$ drop toward zero, thus at $t_{u}^{\prime *}=0$ a positive tax floor is detrimental.

Notice that such a result is general enough to be found in many models of the NEG where governments only tax the mobile factor (in the BK model obviously, but also in the model presented in section 2). 


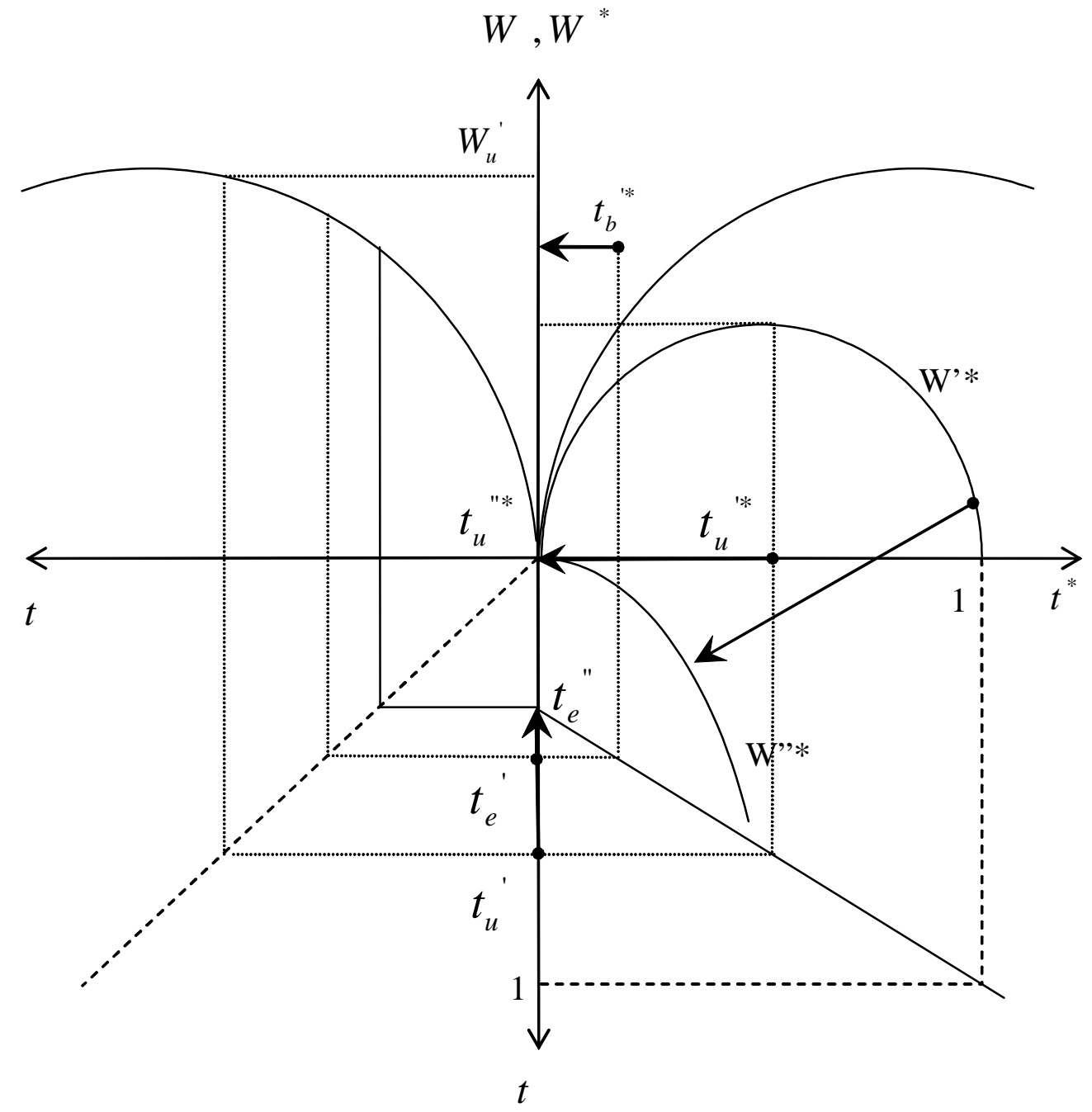

Figure 12: Tax floor scheme for the Periphery

\section{Concluding remarks}

In the tax competition literature of the New Economic Geography, agglomeration generates a rent that is bell-shaped with respect to trade liberalization, and as a direct implication when trade between nations starts to be liberalized, the Core can increase its tax rate without losing activities. In this literature, the hump-shaped agglomeration rent comes from the dispersive force consisting of the demand of immobile farmers. As has been pointed out by Helpman [1998, p54] this "centrifugal force $[\ldots]$ is particularly suitable for societies in which agriculture plays a major role, and in which farmers are tied to their land", but alternative modeling are also relevant, as it has been underlined by Cavailhès et al. [2004] 40\% of the income of 
American households is spent on housing and transportation and a similar percentage can be found for the average of the 15 European Union member states (Winqvist $[1999])^{23}$, then urban costs represent a significant feature of developed societies. As a result, we have chosen to analyse a model that emphasizes commuting costs as a dispersive force. We have proved that dispersion Pareto dominates agglomeration and we have shown that the agglomeration rent strictly decreases with regional and international trade liberalization. Then, if the Core can set a higher tax rate than the Periphery without tax-base loss, this tax must converge toward that of its adversary when trade is liberalized. Actually, the conclusions of the basic tax competition model also tend to be verified in a lumpy world with partial and total agglomeration: tax competition leads regions to a race to the bottom. Lastly, and even if our model is much fitter to describe the city or the regional level, it is tempting to link its conclusions concerning the zero tax rate set by the Periphery to the $0 \%$ tax rate set by Estonia on retained earnings. This model also warns about the possibility of setting a positive tax floor for the smaller region. Indeed if this is done when juridictions are specialized in the taxation of the mobile factor, then this floor can be too high and harmful to the Periphery. Except this last extension concerning welfare, the present work was essentially positive, the next step is thus to follow Ottaviano et van Ypersele [2005] in order to tackle normative questions concerning the desirability of tax competition at the urban scale. To paraphrase the authors we would like to ask the two following questions: does tax competition distort the national allocation of labour, thus yielding an inefficient regional specialization in production? Does tax competition distort the pattern of local trade, thus yielding inefficient shipment of goods between cities?

Acknowledgement : The author is particularly grateful to Marc Fleurbaey, Carl Gaigné, Frederic Robert-Nicoud and Jacques Thisse for helpful comments and suggestions. I also thanks the two anonymous referees for interesting remarks.

\footnotetext{
${ }^{23}$ In the particular case of France, and by using the INSEE housing survey, Cavailhès et al. report that rent which reprensented $27 \%$ of income in 1984, has rosen to $70 \%$ in 1996 . Furthermore, by introducing their measure of commuting costs they show that the budget share of transport communication and rent is effectively around $40 \%$ in 1996.
} 


\section{A The break point}

A total differentiation of the equilibrium around the symmetry gives:

$$
\begin{aligned}
\widehat{w} & =\frac{Z}{\sigma}(\widehat{Y}+(\sigma-1) \widehat{P}) \\
\widehat{P} & =\frac{Z}{1-\sigma}(\widehat{L}+(1-\sigma) \widehat{w}) \\
\widehat{Y} & =\widehat{L}+\widehat{w} \\
\widehat{\omega} & =\frac{\widehat{w}}{\widehat{h}}-\frac{\widehat{P}}{\widehat{h}}-\frac{\theta}{4-\theta},
\end{aligned}
$$

with $Z_{\phi}$ given by:

$$
Z_{\phi}=\frac{1}{2}\left(\frac{w}{P}\right)^{1-\sigma}(1-\phi)
$$

where wage and price are given at the symmetric equilibrium by:

$$
\begin{aligned}
w & =\left[\phi^{\circ} \frac{Y^{\circ}}{\sigma f\left(P^{\circ}\right)^{1-\sigma}}+\frac{Y}{\sigma f P^{1-\sigma}}\left(1+\phi_{b}\right)\right]^{1 / \sigma} \\
Y & =(1-\theta / 4) w / 2, \quad Y^{\circ}=L^{\circ} \\
P & =\left[\left(L^{\circ} \phi^{\circ}\left(w^{\circ}\right)^{1-\sigma} / \sigma f\right)+\left(L w^{1-\sigma}\left(1+\phi_{b}\right) / \sigma f\right)\right]^{1 / 1-\sigma} \\
P^{\circ} & =\left[\left(L^{\circ}\left(w^{\circ}\right)^{1-\sigma} / \sigma f\right)+\left(2 \phi^{\circ} L w^{1-\sigma} / \sigma f\right)\right]^{1 / 1-\sigma} .
\end{aligned}
$$

We insert (37) into (35), and rewrite (35) and (36) as the following system:

$$
\left[\begin{array}{cc}
\sigma-Z_{\phi} & (1-\sigma) Z_{\phi} \\
(\sigma-1) Z_{\phi} & 1-\sigma
\end{array}\right]\left[\begin{array}{l}
\widehat{w} \\
\widehat{P}
\end{array}\right]=\left[\begin{array}{c}
Z_{\phi} \widehat{L} \\
Z_{\phi} \widehat{L}
\end{array}\right]
$$

by using the Cramer rule, this system can be written:

$$
\begin{aligned}
\widehat{w} & =\frac{1}{\Delta}\left[\begin{array}{cc}
Z_{\phi} \widehat{L} & (1-\sigma) Z_{\phi} \\
Z_{\phi} \widehat{L} & 1-\sigma
\end{array}\right]=\frac{Z_{\phi} \widehat{L}}{\Delta}(1-\sigma)\left(1-Z_{\phi}\right) \\
\widehat{P} & =\frac{1}{\Delta}\left[\begin{array}{cc}
\sigma-Z_{\phi} & Z_{\phi} \widehat{L} \\
(\sigma-1) Z_{\phi} & Z_{\phi} \widehat{L}
\end{array}\right]=\frac{Z_{\phi} \widehat{L}}{\Delta}\left(1-Z_{\phi}\right) \sigma \\
\text { with } \Delta & =\left(1-Z_{\phi}\right)\left[\sigma+Z_{\phi}(\sigma-1)\right](1-\sigma) .
\end{aligned}
$$

From eq.(2) we know:

$$
\begin{aligned}
\widehat{L} & =Z_{\theta} \widehat{h} \\
\text { with } \quad Z_{\theta} & =\frac{1-\theta / 2}{1-\theta / 4} .
\end{aligned}
$$


By inserting this into the previous system (39) (40), and by using this equation ((39) (40)) with (38) we get:

$$
\frac{V \widehat{(1 / 2, \phi})}{\widehat{h}}=\frac{Z_{\theta} Z_{\phi}\left(1-Z_{\phi}\right)(1-2 \sigma)}{\Delta}-\frac{\theta}{4-\theta}
$$

simplifying with the determinant gives:

$$
\frac{V \widehat{(1 / 2, \phi)}}{\widehat{h}}=Z_{\theta}\left[\frac{Z_{\phi}(1-2 \sigma)}{\left[\sigma+Z_{\phi}(\sigma-1)\right](1-\sigma)}-\frac{\theta}{2(2-\theta)}\right] .
$$

Clearly when $Z_{\phi}=0$, any deviation from the dispersive equilibrium has a negative impact on net wage. More precisely:

$$
\frac{V \widehat{(1 / 2, \phi)}}{\widehat{h}}<0 \Leftrightarrow \frac{Z_{\phi}(1-2 \sigma)}{\left[\sigma+Z_{\phi}(\sigma-1)\right](1-\sigma)}<\frac{\theta}{4-2 \theta} .
$$

Which gives

$$
\frac{V \widehat{(1 / 2, \phi)}}{\widehat{h}}<0 \Leftrightarrow Z_{\phi}<\frac{\sigma(1-\sigma) \theta}{(\sigma-1)^{2} \theta-(2 \sigma-1)(4-2 \theta)} .
$$

The dispersive equilibrium is thus stable if and only if

$$
Z_{\phi}<Z_{\phi}^{b}=\frac{\sigma(1-\sigma) \theta}{(\sigma-1)^{2} \theta-(2 \sigma-1)(4-2 \theta)}
$$

Furthermore $Z_{\phi}$ is a decreasing function of $\phi$, thus:

$$
Z_{\phi}<Z_{\phi}^{b} \Leftrightarrow \phi>\phi_{b}
$$

The dispersive equilibrium is therefore stable when $\phi>\phi_{b}$.

\begin{tabular}{|c|c|c|c|c|c|}
\hline & & $\begin{array}{c}\phi=1.8^{-4} \\
(\simeq 0.09) \\
\theta=0.4 \\
L^{\circ}=3\end{array}$ & $\begin{array}{c}\phi=1.5^{-4} \\
(\simeq 0.2) \\
\theta=0.4 \\
L^{\circ}=3\end{array}$ & $\begin{array}{c}\phi=1.8^{-4} \\
\theta=0.5 \\
L^{\circ}=3\end{array}$ & $\begin{array}{c}\phi=1.8^{-4} \\
\theta=0.4 \\
L^{\circ}=2\end{array}$ \\
\hline$\phi^{\circ}=1.7^{-4}$ & $V(1 / 2)$ & 0.545 & 0.555 & 0.526 & 0.536 \\
\hline$(\simeq 0.12)$ & $V(1)$ & 0.537 & 0.537 & 0.496 & 0.530 \\
\hline$\phi^{\circ}=1.5^{-4}$ & $V(1 / 2)$ & 0.570 & 0.580 & 0.552 & 0.556 \\
\hline$(\simeq 0.2)$ & $V(1)$ & 0.557 & 0.557 & 0.516 & 0.546 \\
\hline
\end{tabular}

\section{B Welfare analysis}

In this appendix we want to check the result observed in Figure 3 concerning individuals welfare under agglomeration, $V(1)$, and dispersion $V(1 / 2)$. Then Table 1 reports $V(1)$ and $V(1 / 2)$ for different values of $\tau, L^{\circ}$ and $\tau^{\circ}$.

Table 1 : Individual welfare under agglomeration and dispersion. 
In all cases reported in Table 1, and thus whatever the value of parameters, we get $V(1 / 2)>V(1)$, which confirms the result found via the Figure 3 : dispersion Pareto dominates agglomeration. Furthermore we can remark that stronger are internal costs, stronger the Pareto domination (compare column 1 and 2), indeed when internal costs increase the welfare under agglomeration is not affected since all domestic goods are produced locally, while under dispersion an increase of these costs reduces the individual welfare since the price of the imported goods increases. Lastly the higher the size of the rest of the world (compare column 4 and 1), and the higher the international trade freeness (compare line 1 and 2), the higher commuting costs (compare column 3 and 1), the more dispersion is preferred to agglomeration.

\section{Tax Gap}

The tax gap presented in Figure 10 depends on some of the parameters in the model. This dependence is summarized in Table 2 which reports this tax gap at different values of $\tau, L^{\circ}$ and $\tau^{\circ}$.

Table 2: The tax gap $t_{e}-t_{u}^{*}$ for different values of $\tau, L^{\circ}$ and $\tau^{\circ}$.

\begin{tabular}{|c|c|c|c|c|}
\hline & $\begin{array}{c}\phi=1.8^{-4} \\
(\simeq 0.09) \\
\theta=0.1 \\
L^{\circ}=2\end{array}$ & $\begin{array}{c}\phi=1.5^{-4} \\
(\simeq 0.2) \\
\theta=0.1 \\
L^{\circ}=2\end{array}$ & $\begin{array}{c}\phi=1.8^{-4} \\
L^{\circ}=2\end{array}$ & $\begin{array}{c}\phi=1.8^{-4} \\
\theta=0.1 \\
L^{\circ}=4\end{array}$ \\
\hline $\begin{array}{c}\phi^{\circ}=(1.7)^{1-5} \\
(\simeq 0.12)\end{array}$ & 0.144 & 0.052 & 0.109 & 0.085 \\
\hline$\phi^{\circ} \begin{array}{c}(1.55)^{1-5} \\
(\simeq 0.17)\end{array}$ & 0.088 & 0.001 & 0.057 & 0.011 \\
\hline$\phi^{\circ}=(1.4)^{1-5}$ \\
$(\simeq 0.26)$
\end{tabular}

In the Table 2, the first column is our benchmark, in the second one we analyze the impact of an increase in congesting costs and in the third one we test a growth in the population of the rest of the world. Whatever the column, the tax gap $t_{e}-t_{u}^{*}$ decreases with respect to trade freeness $\phi^{\circ}$ and then confirms proposition 6 . Furthermore an increase in the internal trade freeness $\phi$, or in the size of the rest of the world $L^{\circ}$, tends to decrease the tax gap for a given value of $\tau^{\circ}$ which indicates that a race to bottom is more virulent with the rise of these parameters. The reason of such a result is that an increase in $\phi$ or in $L^{\circ}$ tends to reduce the benefit given by the 
partial agglomeration, and then the power to maintain an important and positive tax gap.

\section{References}

ANDERSSON F. and FORSLID R. [2003], Tax competition and economic geography, Journal of Public Economic Theory 5, p. 279-304.

BALDWIN R.E. and FORSLID R. [2002], Tax competition and the nature of capital, CEPR discussion paper 3607.

BALDWIN R.E., FORSLID R., MARTIN P, OTTAVIANO G.I.P. and ROBERTNICOUD F. [2003], Economic geography and public policy, Princeton University Press, Princeton NJ USA.

BALDWIN R.E and KRUGMAN P. [2004], Agglomeration, integration and tax harmonization, European Economic Review 48, p. 1-23.

BESLEY T. and SMART M., 2007. Fiscal restraints and voter welfare, Journal of Public Economics, vol. 91(3-4), p. 755-773.

BORCK R. and PFLUGER M. [2006], Agglomeration and Tax Competition. European Economic Review 50, p. 647-668.

BRETSCHGER L and HETTICH F. [2002] Globalisation, capital mobility and tax competition: theory and evidence for OECD countries. European Journal of Political Economy 18, p. 695-716.

BRULHART M and JAMETTI M. [2007] Does Tax Competition Tame the Leviathan? CEPR discussion paper 6512.

BUCOVESTKI S. [1991] Asymetric Tax Competition. Journal of Urban Economics 30, p. 167-181.

CANDAU F. [2008.a], Location Choice and Public Policies, a Survey of the NEG. Forthcoming in Journal of Economic Surveys.

CANDAU F. [2008.b], Good Governance Trade and Integration. Forthcoming in Papers in Regional Science.

CAVAILHES J., GAIGNE C. and THISSE J-F. [2004], Trade costs versus urban costs, CEPR discussion paper 4440.

CHARLOT S., GAIGNE C., ROBERT-NICOUD F. and THISSE J-F. [2006], Agglomeration and Welfare: the core-periphery model in the light of Bentham, Kaldor, and Rawls. Journal of Public Economics 90, p. 325-47.

DIXIT .K. and STIGLITZ J.E. [1977] Monopolistic competition and optimum product diversity. American Economic Review. 67, p. 297-308.

EDWARDS, J., KEEN, M., [1996] Tax competition and Leviathan. European Economic Review 40, 113- 134. 
FORSLID R., and OTTAVIANO G.I.P., [2003] An analytically solvable coreperiphery model, Journal of Economic Geography 3, p. 229-240.

FUJITA, M., KRUGMAN P., VENABLES T., 1999, The spatial economy. Cities, regions and international trade, Cambridge, MIT Press.

FUJITA M. and MORI T. [2005], Frontiers of the New Economic Geography. Papers in Regional Science 84 p. 377-405.

FUJITA M. and THISSE J-F. [2002] Economics of agglomeration. cities, industrial location, and regional growth. Cambridge University press.

GAIGNE C. [2006] The 'genome' of Neg models with vertical linkages. A comment on the welfare analysis. Journal of Economic Geography 6, 141-159.

HELPMAN H. [1998], The Size of Region, In: D. Pines, E. Sadka, and I. Zildcha (eds.). Topic in public economics. Theorical and Applied Analysis. Cambridge: Cambridge University Press, p. 33-54.

KIND H., MIDELFART-KNARVICK K. and SCHELDERUP G. [2000], Competing for capital in a 'lumpy' world, Journal of Public Economics 78, p. 253-274.

KIRCHGASSNER G. and POMMEREHNE W., [1996] Tax harmonization and tax competition in the European Union: lessons from Switzerland. Journal of Public Economics 60, p. 351-371.

KRUGMAN P., [1991], Increasing Returns and Economic Geography, Journal of Political Economy 99, p. 483-499.

KRUGMAN P. and R. LIVAS, [1996], Trade policy and the third world metropolis. Journal of development Economics 49, p. 137-150.

LUDEMA R. and WOOTON I. [2000], Economic geography and the fiscal effects of regional integration, Journal of International Economics 52, p. 331-357.

MONFORT P. and NICOLINI [2000], Regional Convergence and International Integration, Journal of Urban Economics 48, p. 286-306.

MURATA Y. and THISSE J-F., [2005] A simple model of economic geography à la Helpman-Tabuchi, Journal of Urban Economics, p. 137-155.

OTTAVIANO G.I.P., TABUCHI T. and THISSE J-F. [2002], Agglomeration and trade revisited, International Economic Review 43, p. 409-436.

OTTAVIANO G.I.P. and VAN YPERSELE T. [2005], Market access and tax competition, Journal of International Economics 67, p. 25-46.

TABUCHI T., [1998], Urban agglomeration and dispersion: a synthesis of Alonso and Krugman, Journal of Urban Economics 44, p. 333-351.

TOLLEY G. and CRIHFIELD J. [1987], Cities size and place as policy issues. In E. S. Mills (ed.) , Handbook of Regional and Urban Economics, Vol. II. Amsterdam: Elsevier.

WELLISH D. [2000], Theory of public finance in a federal state. Cambridge University Press. 
WILSON J.D. [1991], Tax competition with interregional differences in factor endowments. Regional Science and Urban Economics 21, p. 423-452.

WINQVIST K. [1999], Le consommateur européen en 1994. Eurostat, Statistique en bref, population et conditions sociales.

ZODROW, G.R., MIESZKOWSKI, P., 1986. Pigou, Tiebout, property taxation, and the underprovision of local public goods. Journal of Urban Economics 19, 356370 . 